\title{
Entrepreneurship as Trust
}

forthcoming in 'Foundations and Trends in Entrepreneurship'

$2^{\text {nd }}$ of August 2019

Tomasz Mickiewicz

Aston University,

Aston Triangle,

Birmingham,

B4 7ET

UK

t.mickiewicz@aston.ac.uk

Anna Rebmann

King's College London,

30 Aldwych,

London,

WC2B 4BG

$\mathrm{UK}$

anna.rebmann@kcl.ac.uk

\section{Abstract}

Trust is a critical component of our relationship with others. It forms a basis of not only social relations but also economic ones. Trust is necessarily linked to entrepreneurship because it is useful in conditions of uncertainty. An entrepreneur needs to gain trust of others who cannot obtain full knowledge on what is being introduced to the market as well trust others such as partners, employees and suppliers to deliver on promises. This study aims to examine the role of trust in entrepreneurship. After reviewing the conceptualisation of trust, we argue that trust should be seen in the context of a wider-set of entrepreneurshipsupporting values. We then explore different types of trust and their role in entrepreneurship, moving from particular trust to extended trust, ending with a discussion on how new technology is enabling entrepreneurs to create a new form of distributed trust between strangers.

Key words: Trust, Values, Uncertainty, Entrepreneurship, Effectuation, Family Business, New technology, Blockchain 


\section{Contents}

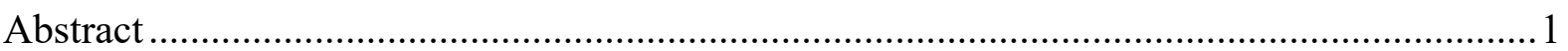

1. Entrepreneurship emerges under the conditions of uncertainty, to which trust is a response 3

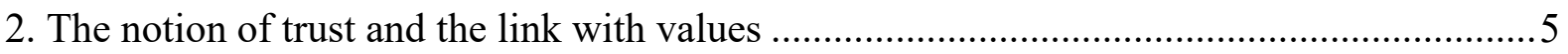

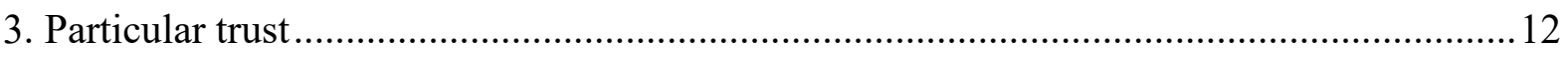

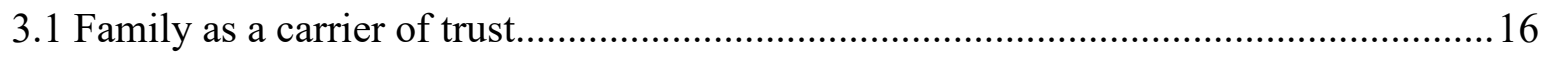

3.2 Effectuation and trust-building as part of the entrepreneurial process........................21

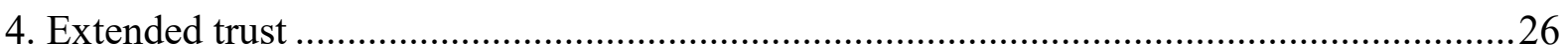

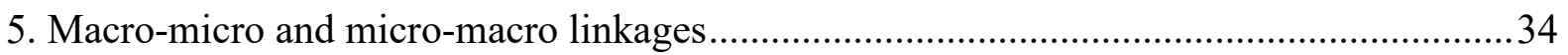

6. The role of new technology in enhancing (or replacing) trust..........................................40

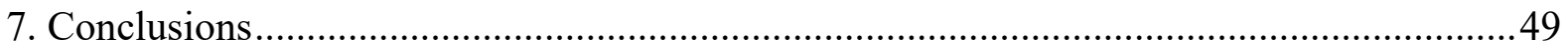

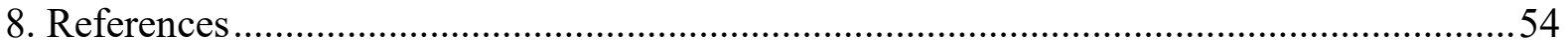




\section{Entrepreneurship emerges under the conditions of uncertainty, to which trust is a response}

As argued by Knight (1921/2009), handling uncertainty is a distinctive function of entrepreneurs. The space for entrepreneurship emerges when ambiguity present in the economic environment cannot be fully translated into risk: that is, ambiguity cannot be quantified and therefore cannot be insured against. Furthermore, the uncertainty is further amplified by an element of novelty associated with any new venture.

These conditions of uncertainty also explain why trust is central to any entrepreneurial activity. An entrepreneur needs to gain trust of others who cannot obtain full knowledge on what is being introduced to the market; and here the others are both potential customers, and those who provide resources to the new venture, including finance, work and skills, either as the members of the entrepreneurial team, or as employees. In these new relations of trust, the entrepreneur appears as trustee, yet $\mathrm{s} / \mathrm{he}$ is also a trustor: building her/his business, s/he gradually places trust in other people on whose actions the venture development relies. ${ }^{1}$ Thus, trust building is an important component of the entrepreneurial process: entrepreneurship is more than trust, but trust remains at its core. The latter reduces the (perceived) level of uncertainty (Mayer et al., 1995) enabling entrepreneurial entry.

Welter (2012: 194) summarises the linkages between trust, entrepreneurship, and uncertainty:

'When pursuing entrepreneurial activities and trusting, individuals deal with the unknown; when acting entrepreneurially, we do not know whether we will achieve the

\footnotetext{
${ }^{1}$ For the detailed discussion of the concepts of trustor and trustee, see Coleman (1990).
} 
intended results; and when trusting, we do not know whether the persons in whom we trust will be worthy of it.'

Similarly, Möllering (2014: 14-15) notices:

'uncertainty, combined with vulnerability, is a general precondition for trust to be relevant /.../ we are not simply talking about bounded rationality but about radical, Knightian uncertainty which renders calculation impossible by definition (rather than by practical limitation).'

Here, Möllering (2014) introduces another element to the discussion. If uncertainty cannot be reduced to risk, that also implies lack of calculativeness. He considers the role of calculativeness (and of utility maximisation) in individual trust, and questions the assumptions adopted by Williamson's (1993) transaction cost theory and other economists (e.g. Gambetta, 1988) who conceive of trust as a purely rational, self-interested and calculative behaviour, where the possible gains from trusting behaviour are weighed up against risk of losses. In contrast with this, Möllering argues against reducing trust to calculative element.

When we accept this proposition, it renders serious implications for how we theorise entrepreneurship. If entrepreneurial decision-making cannot be reduced to calculativeness, this also implies that the utility maximisation is a model that cannot capture the phenomenon of entrepreneurship in full (McCloskey, 2006, 2010, 2016). Applying McCloskey's rhetoric: entrepreneurial values cannot be reduced to prudence (wealth maximisation), and if we accept this then our understanding of the motivation to enter entrepreneurship and to engage in entrepreneurial actions is richer. This applies less to other types of economic activity where uncertainty is lower; there the role of calculativeness may still dominate.

Thus, it is the phenomenon of uncertainty and of trust as response to uncertainty, which makes entrepreneurship a distinctively different domain of research compared with economics. The 
former has to be based on richer assumptions related to human action than the latter. This is also a reason why entrepreneurship remains a multidisciplinary field of study, as this review of entrepreneurship and trust will modestly exemplify.

\section{The notion of trust and the link with values}

Trust is a critical component of our relationship with others. It forms a basis of not only social relations but also economic ones; moreover it can be transferred between these two domains. ${ }^{2}$ As just discussed, to start a business, entrepreneurs need to trust others such as co-founders, co-workers, business partners and at the same time need to be trusted by these people, as well as by others, such as providers of finance and customers. Yet whilst trust is a word that we use commonly in everyday speech, defining it has led to many debates. In this section, we give an overview of the discussion surrounding the definition of trust. In particular, we will review the ways that trust has been theorised, but we will relate these back to the debates in the entrepreneurship literature.

We first need to note trust's relation to social capital. The latter is seen either as a wider concept that can encompass both trust and structural measures such as networks or participation in social organisations (Putnam, 2000), or alternatively it is seen as a separate phenomenon that takes trust as a prerequisite (Coleman 1990). The latter perspective, also implicit in Banfield's (1958) seminal contribution, takes trust and generally the prevailing social attitudes, values and beliefs supporting common action (Guiso, et al., 2010) as the basis for potential for social cooperation. In that sense, trust may be seen as the more fundamental of these. This may also

\footnotetext{
${ }^{2}$ This idea of transferability of values and attitudes supporting human cooperation between business, social and political domains can be traced back to Tocqueville (1835/2003).
} 
motivate focusing on trust first. Nevertheless, we will keep both perspective in minds. At the same time, in this review we will not be covering social capital in detail as it is a large topic in itself.

Turning to definitions of trust, Nooteboom (2002: 45) provides an overarching definition that integrates many perspectives:

'Trust in things or people entails the willingness to submit to the risk that they may fail us, with the expectation that they will not, or the neglect or lack of awareness of the possibility that they might.'

In this definition, trust is conceptualised as an expectation that things will not go wrong; but more than this: the trustor is willing to put her/himself in a situation of dependency where the trustee may fail her/him. Trust, in this perspective, is a feature of a relationship and is very much contextual, it is an interaction of someone having trust, in something, in some respect and under some conditions. This is different to conceptualisations of trust as a personality trait, as has been used by some in the literature (e.g. Caliendo et al., 2012), where an individual is seen as having a propensity to trust and the latter is seen as stable across situations. In our interpretation and others such as Mayer et al. (1995), strictly speaking, personality will be seen as a factor of trust, not trust. Propensity to trust is related to certain behaviours; for example Caliendo et al. (2012) find that individuals with a higher propensity to trust are more likely to become entrepreneurs (enter self-employment) compared to the general population (although no statistically significant effect is found for the probability of being in self-employment). They also show that entrepreneurs are more trustful than both employees and managers.

Yet, by itself, the psychological propensity perspective, while valuable, is insufficient to understanding trust. Any account of trust must acknowledge that trust varies over situations (Mayer et al. 1995), for example, you may trust your close friend to repay a loan but not feel the same level of trust towards a stranger. Thus, while propensity enhances trust, the latter is 
always specific to social or business relation. Moreover, this propensity is only partly explained by individual factors, as culture appears as a strong factor of trust. In Bertrand and Schoar's (2006) econometric experiments, micro factors account for only $11 \%$ of explained variance in trust towards strangers, compared with $89 \%$ of its explained variance being attributed to the country level.

One key, situation-specific, factor of trust is the trustworthiness of the trustee (Mayer et al. 1995; Nooteboom, 1996). Tillmar (2006: 95) expands on the trustor's perception of the three potential characteristics of the trustee in the trust relation, emphasising that "trust may concern the idea that the trustee's behaviour reflects goodness (or benevolence), capability (cf. Nooteboom 1996) and/or commitment (Pettersson 1999)." This is very similar to Mayer et al. (1995), a source cited by many. Here, trust is based on perception of the trustor that the trustee has three essential characteristics (Mayer et al. 1995):

1) ability; that is, a belief that the trustee possesses the right knowledge or ability to accomplish the task at hand;

2) benevolence; that is, there is a desire on the part of the trustee to act in a way that is beneficial to the trustor regardless of personal or economic benefits of the former; 3) integrity, which occurs when the trustor perceives that the trustee adheres to a set of principles and that the principles are acceptable to the trustor; another words, the trustor perceives that the trustee will do 'the right thing'.

Sztompka (1999) makes a similar distinction and also argues that these can be placed on a scale from the least demanding expectation - ability (what he calls 'instrumental trust') - to the most demanding expectations - benevolence (what he calls 'fiduciary trust'). In Sztompka's view, trustors do not always have to hold all three types of trust. Trust in ability can be enough for the trustor to go forward in a transaction and does not always require the expectation of benevolence as the trustee can be motivated by their own self-interest to complete the agreed 
transaction. Yet, when other elements are present, these characteristics of the trustee relate not only to competence but also to moral values (good will), echoing Banfield (1958). Thus, these values become the core factor of the trustfulness (Möllering, 2014). Furthermore, the key issue here seems this: as soon as we talk about moral values, we need to notice that these are culturally shared, and that implies that even if we focus on the dyadic relations between trustees and trustors, the wider, social or cultural perspective is always in the background. At the same time, we may note that focusing on the characteristics of the trustee does yet not imply any values adhered to by the trustor. A trustor may be taking advantage of trustees in a purely instrumental way. ${ }^{3}$ Yet is taking advantage of trustees the norm or the exception?

We may return to the point we made earlier. Uncertainty implies that entrepreneurship cannot be explained solely in terms of calculativeness. This does not yet suggest that entrepreneurial values that drive those who create new venture extend beyond income maximisation: an expected income may be difficult to quantify but it may still remain an objective. Generally, the discussion on comparison of (rationally) expected income and expected wealth of entrepreneurs versus that of employees remains inconclusive (Parker, 2018), and therefore it is hard to conclude either way. But here we may also notice, however, what comes from empirical research on entrepreneurship: self-reported human motivation to become an entrepreneur goes beyond wealth maximisation (Stephan et al., 2015). Entrepreneurs are typically driven also by something else than money. One may call this something else 'preferences' (Schulze et al., 2001) as economists tend to do, but this is just a technical term that calls for further explanation.

\footnotetext{
${ }^{3}$ From a personal experience of one of the authors: I remember a neighbour who befriended Jehovah witnesses for purely opportunistic motives, as they proved very helpful with some everyday business. She openly boasted about taking advantage of them, laughed at them, yet they had her full trust.
} 
What shapes preferences are values. ${ }^{4}$ And importantly, it is an entrepreneurial situation of uncertainty that helps us to identify that there are other values in operation, beyond prudence (wealth maximisation).

Furthermore, if we now assume that entrepreneur is oriented by additional values that extend beyond wealth maximisation or (beyond prudence in McCloskey's (2006) terminology) that would also apply to the entrepreneur's role as the trustor in business relations with others. We already signalled above that trust, including entrepreneurial trust, links with values. Attitudes towards others are driven by values, and more specifically, prudence is accompanied by solidarity (McCloskey, 2006). It is solidarity as a value that may underpin trust; this observation immediately suggests why the latter in turn becomes a foundation of social capital. Yet, are there are other values beyond solidarity we could consider in this context?

One answer is sketched in Mickiewicz et al. (2016): orientation on others, which implies other-regarding attitudes, goes hand in hand with openness, intellectual curiosity about the outside world, and innovativeness. Taking this perspective leads to another deep link between entrepreneurship and trust. Entrepreneurship has always an element of innovation, and the latter implies openness. The openness to new ideas comes hand in hand with openness and tolerance towards others, who are carriers of the ideas, and therefore it may go hand in hand

\footnotetext{
${ }^{4}$ While it may lead us too far away, there is also a confusion related to 'rationality'. For example Nooteboom (2002, p. 509) criticises Williamson, but still contrast 'norms' with 'rationality'. This follows from the old Weberian concept of separating rationality from values (Weber (2017[1924]); for criticism of Weber, see e.g. Strauss, 1953). For an approach, where values and norms form a part of an integrated rational discourse, unlike preferences, see e.g. Dworkin (1977) and Sen (2009); similar approach is implicit in much of McCloskey work, most directly in her (2006) book. In the context of entrepreneurship, Corbetta and Salvato (2004) also adopt a wider concept of rationality, which includes both self-actualisation, and alignment with objectives of others, including those commonly shared in an organisation.
} 
with other-regarding motivation (solidarity). These two elements of value map are neighbours to each other: in Schwartz (e.g. 2011) categorisation, self-transcendence is situated next to openness to change.

Parallel to this, optimism is another aspect of values that is shared between trust and entrepreneurship. Schwartz (2011) will have it under 'mastery', McCloskey (2006) under bourgeois 'courage' (in contrast with the aristocratic version of the latter).

Conceptualisation of trust as 'going beyond self-interest' is not novel (e.g. Saparito et al., $2004)^{6}$, but what is novel is placing entrepreneurship- and innovation related values next to self-transcendence and other-regarding attitudes as argued by Mickiewicz et al. (2016). And identifying the link between trust and entrepreneurship via values and attitudes leads to a wider

\footnotetext{
${ }^{5}$ The value map we refer to is presented as a circle. If we start with Mastery, and follow anticlockwise, we next have: Hierarchy, Embeddedness, Harmony, Egalitarianism, Intellectual Autonomy, Affective Autonomy, and then we come back to Mastery again (Schwartz, 2011).

${ }^{6}$ Again, here is another place where language is confused, therefore it blurs the issue. '(Rational)-self-interest' is contrasted with other-oriented values (seen as 'affects'). But everything can be interpreted as done in selfinterest. Self-interest may imply sticking to own integrity and some ultimate acts of altruism. The real distinction is in assumptions about goals and objectives or another words, again, about values. Typically, with 'self-interest' the objective is taken as income or wealth, therefore the key issue is to contrast income generation with other objectives. This is the reason why we think that 'prudence' (understood as effective income generation) as used by McCloskey $(2006,2010,2016)$ may be a far better term than 'self-interest'. But the criticism of the identification between self-interest and rationality may go further. For example would we claim that compulsive narcissism (often resulting in some success, thus possibly consistent with self-interest) is rational, while paying attention to others and to public interest is not? Or would we claim that the othersregarding perspective is irrelevant in business activity, because all is covered by complete contracts?
} 
issue of a multidimensional nature of attitudes and objectives that drive entrepreneurial activities, and to the social character of the latter. ${ }^{7}$

This link between trust and entrepreneurship-related values also helps to explain overlapping non-business and business relationships, when trust is borrowed from the former to be used in the latter, but equally trust relations in business activities may be extended to be used in other domains. Möllering (2014), in his review of the discussion on trust and calculativeness provides arguments for rejection of the strict separation of market and non-market relationships. Thus, a call to take trust relations seriously in entrepreneurship becomes a call to notice the social embeddedness of the market- and business transactions, and for noticing the interdependences between the social and business relations and underlying values guiding those.

At the same time trust does not appear in Williamson's (1985), highly influential, transaction costs framework. Nevertheless, for him one central issue is the extent of opportunism. The higher the degree of opportunism, the higher is the need for (costly) formal governance mechanisms and monitoring. He also allows for a possibility that the likelihood of the opportunistic behaviour will diminish with aspects interpreted by others authors as factors of trust, for example, with frequent, transaction-specific business interactions repeated over the long time. But Williamson does not think that the concept of trust is needed to be placed there as intermediating in those casual relations. Indeed, it would not be needed, if human motivation could be reduced to prudence; that is it would not be needed if we would consider genuine other-regarding behaviour, solidarity, and altruism as random, unexplained variation in human attitudes. Thus, in our view, the usefulness of the concept of trust seems to be directly related

\footnotetext{
${ }^{7}$ See Schulze et al. (2001) for interpretation of trust from the self-interest point of view, and their overview of the literature that interprets altruism as self-interest. In our view this is pushing the economic theorising centred on self-interest too far. A theory that can explain everything is empty, because it cannot be falsified (Popper, 1963). This is a different argument about self-interest than the one presented in the previous footnote.
} 
to the fact that it is also an intermediary between the more fundamental values and human motivation and the structures of social cooperation, including entrepreneurship.

Last but not least, as the Noteboom's definition points out, trust can be placed not only in individuals but also in social structures, for example in organisations and institutions. The academic literature has identified a variety of forms of trust according to who or what is being trusted. We can group these forms into two broad categories: particular trust and extended trust (Efendić et al. 2014; Newton and Zmerli, 2011; Rebmann 2015, Uslaner, 2002). In the next sections we will describe these two broad categories of trust and examine their relevance to the entrepreneurship literature.

\section{Particular trust}

Particular trust is trust that occurs between specific individuals and is based on the trustor having some definite knowledge about the trustee. This knowledge can arise either through interactions (process-based trust) or, when trust becomes a bit wider, can be based on particular, known characteristics such as membership of a certain group e.g. gender, age, kinship, ethnicity, religion, citizenship (characteristic-based trust) (Zucker 1986). Zucker (1986) explains the development of characteristic-based trust as due to the fact that certain characteristics are legitimized by society as a basis for social judgement, that is to say that some types of people are seen as more inherently trustworthy than others.

In turn, process-based trust is tied to past- or expected exchange which develops knowledge of the trustee. This requires investment by the trustor in a relationship with the trustee or with others who know the trustee, which enables person- or firm specific information to be gathered (ibid.). For example, business angels get to know entrepreneurs before investing, or relationships between the entrepreneur and a supplier is being built based on their knowledge 
about each other. Repeated interaction may also permit the development of shared interests and values which further increases trust (Gulati and Sytch 2008: 168). Furthermore, trust is built because of the expectation of the relationship continuing into the future (Axelrod 1984; Dixit 2004). Game theory shows that cooperative behaviour can be expected and trust can develop if there is a 'shadow of the future' on the present. The shadow of the future refers to the fact that present payoffs to opportunistic behaviour are calculated in respect to threat of losing future benefits if the relationship ends due the opportunistic behaviour being discovered.

These paths to process-based trust can be extended from a bilateral relationship to multilateral relationships where then reputation becomes the mechanism by which two parties who don't know each other can develop trust from their relationships with a third party (Axelrod 1984). These informal process-based mechanisms of producing trust often take long periods of time to build or require commitment over a long period of time and requires some degree of stability in the relationships therefore in such a case, trust is limited to a small number of individuals (Lane 1998; Sztompka 1999; Zucker 1986). The trust developed also tends to be highly specific based on idiosyncratic norms which are bound to the particular type of transaction (Zucker 1986). However, particular trust can be less costly in supporting transactions than formal control mechanisms which is why for example business angels (BAs) are more likely than venture capitalists (VCs) to rely on trust to reduce relational risks in investment rather than on formal procedures, such as controls such as requiring the investor sign off on certain decisions. This is possible, because unlike VCs, BAs do not need to explain their investment decisions to third parties as they are using their own money for the investment (Maxwell and Levesque, 2014). Thus relying on interpersonal trust is a more suitable and less costly as means of reducing relationship risk (transaction costs) between the BA and the entrepreneur. Building such structures of particular trust may also substitute for consulting formalised sources of information about potential business partners, for example on credit 
scores, implying degree of trustfulness; the formalised sources may also simply not be available for (potential) entrepreneurs.

Characteristics-based trust relies on attributes which are ascribed to a person due to for example their family background, ethnicity, or sex. Alternatively, it may also rely on attributes that are acquired (e.g. formal education, business experience). Both do not require extensive investment in information gathering as a condition to establish trust relationship, as such attributes are easily observed or verifiable. Trust relation may be based only on the attributes of the trustee, or on both the attributes of the trustee and the trustor, when it is based on social similarity (homophily) between the trustor and the trustee: 'similarity breeds connection' (McPherson et al., 2001: 415). That comes under the premise that this similarity in easily observable attributes implies similar values and norms and thus the expected outcome of any exchange will be satisfactory to all. In the entrepreneurship literature, we see examples of ascribed characteristics aiding entrepreneurs obtain finance. For instance, Bengtsson and Hsu (2015) find that if the entrepreneurial founder share the same ethnicity as the VC partner, then there is greater likelihood that the VC firm will invest in the start-up, at an earlier stage as well as with a greater size and scope of investment. Additionally, Johnson et al. (2018) find that female entrepreneurs do better in early-stage crowdfunding than male entrepreneurs and hypothesise this is because women are seen as inherently more trustworthy. This example is important, as it demonstrate that while particular trust is often a two-way mutual relation, it may also be one-way, asymmetric (Coleman, 1990): men trusting women does not imply the reverse.

Yet, characteristics-based trust may also lead to over-trust. In studying VCs, Bengtsson and Hsu (2015) also find that investment matches based on share ethnicity actually have less successful company outcomes as they are less likely to attain an IPO or M\&A than investment matches where there is no shared ethnicity. This suggests that co-ethnicity may induce greater 
trust than is warranted and lead to less intensive due diligence or reduce VC monitoring. Similar phenomenon appears in in the context of family firms, which we will discuss in detail in the next section. This also links with debates about whether entrepreneurs generally overtrust: give more trust than an objective appraisal of the situation would warrant (Goel and Karri, 2006; Sarasvathy and Dew, 2008; Karri and Goel, 2008). ${ }^{8}$

Particular trust is an important part of all relationships and thus there is a range of literature which examines the role of particular trust in the entrepreneurial process. Particular trust may play a role already in the early stage enabling the formation of ideas (ideation) supported by discussions with trusted others (Gemmell et al. 2012), and in the later stage of enactment, when it facilitates building needed business networks (Hite, 2005). The literature considers the relationship of particular trust and entrepreneurship in a variety of settings including the entrepreneurial teams (Francis and Sandberg, 2000), business networks (Smith and Lohrke, 2008), customer relationships, and in the provision of finance (Bammens and Collewaert 2014; De Clercq and Sapienza, 2005; Harrison et al. 1997; Moro et al. 2018), and family businesses (Allen et al., 2018; Discua Cruz et al., 2013; Eddleston and Morgan, 2014; Shi et al., 2015), to which we will turn next, as it is an important special topic in entrepreneurship. More generally, particular trust matters most where the time dimension is an important part of the transaction, when assets are easy to expropriate as in provision of finance, or in radical innovation activities where formal governance structures are more difficult to establish due to casual ambiguity (Williamson, 1985).

\footnotetext{
${ }^{8}$ In this case we discuss a (strength of a) disposition to trust. This relates to the issue of personality traits related to trust (Caliendo et al. 2012) that we left aside. The two issues will be related in case we would focus on personality traits as a factor in becoming an entrepreneur. If so, we will observe the entrepreneurs trusting more because of the selection effect.
} 


\subsection{Family as a carrier of trust}

Family is the most fundamental social structure which is a conduit of trust and family firms are the foundational form of organisation for economic development in all countries (Fukuyama, 1995; Soleimanof et al,. 2018). On an even more fundamental level, the core component of trust in a family relates to the altruistic relations between parents and children (Corbetta and Salvato, 2004).

In pre-industrial time, the omnipresent peasant household with division of labour amongst the family can be viewed as an archetype of a family business. Still today, across the world, family businesses are hugely important, representing between 75 to $95 \%$ of registered firms and 65\% of GDP (Fukuyama, 1995; Howorth et al. 2006).

Resource-based theory offers one possible conceptualisation that can be applied to analyse family businesses. It proposes that family firms have some unique bundles of resources compared to non-family firms which are labelled in the family business literature as "familiness" and these can provide a basis for valuable, unique and hard to imitate sources of competitive advantage (Habbershon and Williams, 1999; Peng and Jiang, 2010). In this perspective, trust is one element of the familiness. Relationships between individuals and organisations are part of all businesses, but family businesses involve further ties, beyond business, that bind participants together - the bonds of family which can provide a source of competitive advantage (Steier, 2001). Trust within the family has strong affective foundations; the latter consist of the emotional bonds between individual members, and link with love and friendship (Lewis and Weigert, 1985; McAllistair, 1995). In such situation, individuals 'express genuine care and concern for the welfare of partners, believe in the intrinsic virtue of such relationships, and believe that these sentiments are reciprocated', which then serves as the basis for trust (McAllistair, 1995: 26). 
As observed by Schultze et al. (2001: 102): ' [ $\mathrm{t}$ ]hese bonds in turn, lend family firms a history, language, and identity that make it special.' Due to these special bonds, family firms have reduced principle-agent problems: hiring trusted family members reduces agency costs by alleviating concerns about opportunistic behaviour (Zahra et al., 2004). Furthermore, trust and lower risk of opportunism between family members reduces transactions costs; that is enables adoption of less costly governance structures and gives the family firm access to a wider range of resources. Using a sample of US family businesses, Allen et al. (2018: 43) found positive effects of trust in the top management on firm performance. This process works by inducing higher commitment of the top management team that leads them to fully commit to the family firm, despite the risks and uncertainties that may arise in family firms due to their focus on socio-emotional wealth alongside economic value maximisation. Family-based trust may also imply more innovation in family firms, as trust is particularly important for intangible assets, as already argued above (Calabrò et al., 2018).

Furthermore, not only there may be more trust within the family firms; they may also attract more trust from other stakeholders, and customers in particular. This may result from the phenomenon of humanisation, where family firms are perceived as characterised by stronger human values, perception of 'real' people, friendliness and warmth and generally more opportunities to develop personal relationships towards the firm (Beck and Prügl, 2018; Eddleston et al., 2010).Despite the widespread emphasis on trust as a governance mechanism that gives family businesses a competitive advantage in the family business literature, we should not assume that trust always comes naturally to the family firm and that it dominates the governance structure. But it may be especially important to new firms and therefore to entrepreneurship. As we already mentioned, it takes time to build structures of trust and that relates to any business organisation. Therefore, trust may be underdeveloped in new businesses, and it follows that the latter can benefit from trust early on, if they can borrow trust from 
elsewhere, from family in particular (Arregle et al., 2007). This implies that new family firms may be characterised by lower 'liability of newness'. Data from the Global Entrepreneurship Monitor shows that family ownership of start-ups is a common occurrence - around $48 \%$ of those engaged in current start up initiatives report that more than $50 \%$ of the business is currently owned by family (Matthews et al., 2012).

However, there is the other side of the coin. In their highly cited contribution, Schulze et al. (2001) argue and offer empirical evidence that indicates that while family-based trust alleviates forms of opportunism related to agency problems, it may create risks of opportunistic behaviour elsewhere. They offer a comprehensive list of problems that may emerge. For example, generosity of the owners towards their children or other family members may lead to moral hazard issues, instead of (or alongside) the positive effects of reciprocity. Family members may develop a tendency to free ride. Strong emotional linkages may result in cognitive biases of the owners-managers that could make identifying such problems in timely manner difficult. The owners, and especially parents may find implementing monitoring, disciplining, and enforcing agreements troublesome when such a need arises. Furthermore, once firms hire non-family members, it may be difficult to apply required formalised incentive and pay systems to the outsiders, because such systems should be equally applied to family members as well, and this may cause tension. Last but not least, Schulze et al. (2001) highlights that firing incompetent relatives is particularly difficult, and likewise an incompetent $\mathrm{CEO}$ may remain in the office for too long.

Other authors agree. Steier (2001) calls attention to the fact that whilst trust may be indigenous in most family firms in the early stages of firm development and a source of competitive advantage, as the family firm evolves there are forces that naturally diminish trust. A crucial period of change is during the period of succession when there is leadership transition between generations. During this period trust may diminish as familial ties become 
less strong and conflict over the future of the firm arises. This creates a challenge for family businesses undergoing this transition as they may no longer be able to rely so heavily on trust to economise on formal governance mechanisms and either need to build more costly formal governance structures for the business to survive, or need to invest heavily in trust building activities. In a similar vein, Shi et al. (2015: 834) find that in the move to second-generation family involvement in Chinese private companies, the basis of trust formation changes, with individual competence and contractual commitments playing a greater role. They argue that ' $[\mathrm{t}]$ his has implications on the value system of second-generation Chinese family businesses which was arguably in a transition from a family orientation to a market orientation, particularly in the entrepreneurial processes.'

As well as the nature of trust evolving over time, the role of trust within family businesses depends upon the nature of the relationships within the family. Not all family ties are equally strong; these can vary within families thus different types of governance arrangements occur within family businesses, some more based on trust and some more on formal mechanisms, and some family members may not be invited to participate in the firm (Discua Cruz et al., 2013; Steier, 2001).

Thus, while we have discussed the advantages of family-based trust, there is also literature that clearly shows there are dark sides to it. Over-reliance on family as a trust structure may lead to 'Penrosian effects' (Penrose, 2009[1959]), where family firms find it difficult to expand managerial team in a short run (Arregle et al., 2017). Related to this, in Shi et al.'s (2015) study on second generation Chinese private firms, they notice that 'there is a danger of the negative "strong-tie effect" in the interpersonal trusting relationships. It may restrict these firms to rely on the family-based networks to seek valuable information, acquire and deploy resources, and evaluate and exploit a potential opportunity. This exclusive reliance is likely to result in oversight of opportunities from remote sources, where an established trusting 
relationship is not in place and the tie with the entrepreneur is 'weak' (Granovetter, 1973). Furthermore, unrealistic over-estimate of the family-based competences may lead to extra costs, or even performance failure. The competences are not that easily transferred over the generation, and lack of competence results in negative outcomes. Trust is vulnerable and easy to be damaged in such cases, and repairing it usually requires a high level of commitment and determination (Dyer, 2012).

Arguably, on a societal level there may also be negative effects of strong family-based trust. Fukuyama (1995) argues that "societies that have very strong families but relatively weak bonds of trust among people unrelated to one another will tend to be dominated small, family-owned and managed-businesses" (Ibid.: 49), and have trouble creating larger durable firms. This is in line with empirical correlations established by Bertrand and Schoar (2006): in countries with strong family values, the fraction of self-employed tend to be higher, and the establishment size tend to be smaller. Solimanof et al. (2018) point out that as family firms are embedded with deep local roots they can play a more extensive role in shaping a country's institutions than non-family firms. When family firms tend towards behaviours of favouritism like nepotism and cronyism, these strong family bonds can have a negative influence on the institutional development within a country. Oligarchic control can emerge in less developed countries with weak institutions where powerful and well-connected business families adjust the rules of the game in favour of themselves, making it more difficult for competitors and leading to crony capitalism and the assets and wealth being concentrated into the hands of a few families. Some of these ideas can be traced back to Banfield's (1958) concept of 'amoral familism'; we will return to this theme in Section 4. 


\subsection{Effectuation and trust-building as part of the entrepreneurial process.}

As already argued, the key challenge any entrepreneur and any new business faces is to overcome the liability of newness and therefore to be seen as trustworthy to secure cooperation and resources from others. At the same time, the cooperation also requires becoming a trustor, and that in turn may imply acquiring knowledge and experience needed to trust business partners. It follows therefore, that an important aspect of the new venture formation is building mutual trust. ${ }^{9}$ What traits make the entrepreneur trustworthy and what strategies can she/he use to acquire trustworthiness? And parallel to this, how can she/he build her/his trust in others?

In our view, the effectuation theory represent lenses that are well suited to find some answers to the questions we just asked. Effectuation is a theoretical model that aims to describe the entrepreneurial process, where the stress is on finding the effects and goals with given set of means, instead of simply maximising the predetermined goals. Uncertainty is central to this entrepreneurial process, and the latter progress by identifying and constructing controllable aspects of the generally unpredictable future. In this process, the primary issue that the entrepreneur faces is not the competition from others, but the challenge to build structures of cooperation: forming alliances and securing commitments from stakeholders (Sarasvathy, 2001).

Thus, entrepreneurial process is seen as the dynamics of forming relations with others, and gradually absorbing uncertainty. This leads naturally to focus on the particular, process-based type of trust we discussed above. At the same time, it does not exclude other forms of trust: characteristics-based particular trust may also be relied upon by the entrepreneur, and presence

\footnotetext{
${ }^{9}$ Moreover, there are specific forms of ventures, where trust is the key subject of new activities. Coleman (1990) highlights specific entrepreneurial projects that focus on building structures of trust leading to new value creation. This links for example with projects that build some internet based wide structures of trust; we will return to this issue in Section 6.
} 
of the extended trust (which we will discuss in Section 4) may facilitate building the connections.

There is an ongoing discussion about the role of trust in this process of incremental uncertainty absorption as interpreted by effectuation theory. Sarasvathy and Dew (2008) postulate to limit the use of trust lenses, and also to limit any assumptions about individuals' characteristics, including attitudes, motivation and values. They argue that cooperation is built on incremental basis, 'commitment by commitment - and not by either predicting or assuming trustworthy behavior' (Ibid.: 729; italics their). But Karri and Goel (2008) in their response, defend the role of trust in effectuation, and argue that 'all human action (entrepreneurial or not) requires trust' (Ibid.: 740), while also calling for leaving scope for individuals' characteristics among explanatory variables. They also note that assuming the role for individuals' characteristics is not the same as assuming that these characteristics do not change over time. The latter observation is interesting, as it implies potential feedback effects from the entrepreneurial attitudes towards motivation, including willingness to trust.

One interesting point coming from this discussion is that while facing uncertainty, the question is always: how much is being risked; how much is at stake in terms of potential loss. Sarasvathy (2001) emphasised that the notion of affordable loss is more central to the entrepreneur's decision-making than that of expected returns. The effectuation process takes place over increased, gradual commitment, where vulnerability in each step remains limited (Sarasvathy and Dew, 2008: 731). One may also notice that this links with a more general point: people who are well-endowed are more trusting, because they face lower risks when cheated. In this context, Karri and Goel (2008: 741) talk about 'decision making criteria of affordable loss'; these decision criteria are applied by entrepreneurs when trusting, and a limit of affordable loss becomes a constraint on the extent of trust that is offered by the entrepreneur as a trustor. They summarise their position in the following way: 
'However, our arguments suggest that entrepreneurs differ in their abilities because of the differences in their cognitive reasoning, attitudes, intentions, and behavior. Our position is that a focus on innate psychological traits to the exclusion of everything else is limiting to the advancement of theory building in entrepreneurship. Therefore, it is important to study other characteristics, such as attitudes, cognitions, and reasoning processes of entrepreneurs, with a full recognition that these characteristics are capable of varying over time or over multiple contexts.' (Ibid.: 746)

Thus, mutual trust is built and expanded by the entrepreneur in his/her business relations. A similar theme of the creation of trust being part of the entrepreneurial process appears in Smith and Lohrke (2008: 320): entrepreneurs as 'individual actors can take an active role in developing trust'. Maxwell and Levesque (2014) provide a unique, detailed analysis of how entrepreneurs' behaviour during an initial interaction with a business angel can build trust, or damage and violate trust, affecting whether the business angel will invest. Their research shows that entrepreneurs who exhibit more trust-building behaviours in even a very short time period are more likely to be funded. They provide a detailed schema of trust-building, and of trust damaging and violating behaviour, based on the behaviour of the entrepreneur during the interaction. ${ }^{10}$ Parallel to this, Bammens and Collewaert (2014) also explore the

\footnotetext{
${ }^{10}$ We would like to highlight the innovative research methods used by Maxwell and Levesque (2014). Whereas most trust research relies heavily on the use of surveys, Maxwell and Levesque (2014) use observational interaction to record, code and analyse behaviour during actual BA-entrepreneur interactions which were recorded as part of Canadian Broadcasting Centre's reality TV show 'Shark Tank'. This allows analysis of real-time investment decisions and detailed study of the processes of trust building. It also allows independent observers to extract data instead of relying on self-reporting from the participants, removing self-reporting bias. It also removes hindsight bias, as data is collected over time without knowing the final outcome.
} 
role of trust in building the angel - entrepreneur relationship. They find that having a trusting relationship leads to better communication between the two parties and that it also greater trust on the angel investors' side positively relates to their perceptions of the venture's performance. These perceptions are important to venture survival and performance as they determine whether an angel will continue to refinance the investment or decide to abandon it. This example demonstrates how trust enhances securing commitments from stakeholders.

Moreover, as argued by Tillmar (2006), entrepreneurs may also use various social structures, in which their potential business partners are embedded, and also focus on the ascribed characteristics of the latter in order to leverage trust:

"In the Tanzanian context, small business owners made entrepreneurial use of pre-existing 'rules of the game'. Traditional organizations, such as the tribal communities, were used in new ways for solving business conflicts. Their mechanisms of sanctions enabled some level of trust. The fact that women are fully responsible for their children was used as a natural situation of 'hostage' when female business owners were trusted on the basis that they could not easily disappear from the town. The same applies when business owners with fixed assets, like a house, were trusted since they would not benefit from disappearing from the town." (Ibid., p. 103).

A related important concept in entrepreneurship is that of bricolage: entrepreneurs organising and finding out useful resources from a limited local set, 'making do with what is at hand' (Baker and Nelson, 2005: 329); a process that has often an element of experimenting and novelty in it. What Tillmar (2006) describes above can therefore be labelled as 'trust bricolage': trustfulness of potential (local) partners can be seen as a resource: it needs to be discovered, assessed and incorporated into the entrepreneurial project. At the same time, while the process can be also interpreted as effectuation, in effectuation theory the emphasis 
is on constructing; here the key issue seems to be the capacity of the entrepreneur to identify the pre-existing elements in the local environment that can be turned into useful resources for an entrepreneurial project. Within this perspective, the example by Tillmar (2006) as discussed above can be interpreted as bricolage, where the entrepreneurs leverage social trust structures and the social characteristics of the individuals, for the purpose of business cooperation. Nevertheless, both effectuation and bricolage perspective have much in common as the theories of the entrepreneurial process.

Yet, the process of building and maintaining trust amongst exchange partners can also lead to dysfunctionalities. In exploring trust between angel investors and entrepreneurs, Bammens and Collewaert (2014) find that entrepreneurs trust in the angel is actually negatively related to perceived venture performance as assessed by the angel. They argue this is because entrepreneurs with more trusting relationships wish to protect the trusting bond they have with the angel investor and a key method to do this is to ensure that their behaviour is predictable and consistent. Thus increasing trust with the angel investor "may encourage entrepreneurs to stick to accepted patterns of behaviour and make them less willing to adopt rock-the-boat, deviating actions that may potentially lead the angel investor to question the set of principles guiding their behaviour" (Bammens and Collewaert, 2014: 1989). But this kind of behaviour leads to rigidities, and discourages experimentation and innovation which is needed for entrepreneurial ventures to survive (Ibid.: 1990):

"[W]e would expect the entrepreneurs' sense of being trusted to be the main driver of these rigidities. This is because individuals who feel trusted "recognize that the trust invested in them binds their behavior . . . in a manner that does not violate the expectations of the trusting party". 
Additionally, as already suggested, a trusting relationship can reduce learning and monitoring on the part of the providers of finance (Bengtsson and Hsu, 2015; De Clercq et al. 2005). But this may have some negative implications as well. De Clercq et al. (2005) find that venture capital funds learn less from interacting with portfolio firms in which they have a high level of goodwill trust. Although trust may led to increased communication between investors and entrepreneurs (Bammens and Collewaert, 2014) through increased openness and greater sharing, it may also be that at high levels of trust there is less need to engage in deep discussions, and in such tight relationships people become less critical about each other's actions and more prone to group stereotype thinking (De Clercq et al. 2005).

Overall, incorporating the issue of trust in the theory of the process of new venture creation makes it both richer and more realistic. In this perspective, the issue of trustworthiness is akin to that of legitimacy. The advantage of the language of trust may be however in keeping in mind the two-way nature of trust relations: the entrepreneurs need to build trust in them, but need also to find the trustfulness of the potential partners. The effectuation perspective emphasises the building of the individual trust relations in the entrepreneurial process and may therefore offer useful lenses for that. In contrast, emphasising legitimacy comes at risk of building 'oversocialised' theory (Granovetter, 1973): putting too much stress just on the role of wider social structures and conformity towards those, ignoring the micro aspects of trustbuilding. But there may also be continuity in trust, between its personal and extended forms (Newton and Zmerli, 2011), with the former supporting the latter. And it is now to these wider social structures of trust that we now turn.

\section{Extended trust}

Extended trust has a wider reach and is a more abstract form of trust than particular trust. Here, it is not necessary that the trustor knows the specific characteristics of the trustee 
(Fukuyama, 2001; Raiser, 1999; Rebmann, 2015). Extended trust by a trustor is typically an asymmetric, one way relation: the trustor trusts members of some wider group. And the wide structures of between-groups mutuality in trust may also be analysed (Coleman, 1990). In the context of entrepreneurship, extended trust has been viewed through a psychology lens as personality trait (Caliendo et al. 2012; see above), but it is more commonly analysed as a wider social norm, which helps us to understand the environment in which entrepreneurship takes place and which effects entrepreneurship (Anokhin and Schulze, 2009; Welter 2012; Kwon et al., 2013; Efendic et al., 2014; Pathak and Muralidharan 2016; Churchill, 2017; Mickiewicz et al., 2017). The presence of extended trust sets positive expectations about the supportiveness of the environment; it implies lower perceptions of the risk of opportunism and facilitates individuals' interacting, disseminating information, transacting over resources, and reaching out to wider markets including internationalisation (Domurath and Patzelt., 2016). These positive expectations are shared, and because they are shared the norm of trust can be sustained. Another words, consistency in individual expectations result in stable equilibrium of high trust (or, alternatively, of low trust, as in an environment characterised by corruption, see e.g.: Dixit, 2004).

There are two main forms of extended trust: generalised trust and institutional trust. We will introduce both sequentially, and then we will discuss the linkages between both.

The generalised trust is an inclusive form of trust as it is trusting the general population, implying trust in unknown individuals. Generalised trust is given by the trustor due to confidence in effectiveness of widely shared social norms that discourage opportunism. Yet these shared expectations are about attributes of some social groups that make those trustworthy and therefore the generalised trust is always perceived as implicitly related to some specific social radius. The latter may be wider in some societies, especially in developed as contrasted to emerging markets economies, and narrower in some other, for example in 
societies based on Confucian culture, as claimed by Fukuyama (1995). This also implies that the generalised trust may be incompatible in wider comparisons (Delhey et al., 2011).

The second form of extended trust is institutional trust. Here the object of trust (the trustee) is not a social group, but an institution - a body which makes, implements, and either enforces a society's formal rules - such as government, parliament, the civil service and the judiciary (Rothstein, 2004), or supports norms by sanctions of exclusion - such as a specific church. The focus on the institution implies that there are formal mechanisms by which transactions will be protected and regulated, and that these mechanism are efficient enough to breed trust. However, institutions do not just provide sanctioning but, if they are effective, they are also important in providing a stable normative framework: a reference for 'correct behaviour' in business relationships, which reduces uncertainty as it is easier for firms to assess what other actors will do (Arrighetti et al., 1997). Institutional trust is particularly important as a basis for transactions in the modern economy where people need to transact across group boundaries so cannot rely on within-group trust alone, and when there is increasing diversity in the social groups (Zucker 1986). This diversity can take many forms: ethnic, occupational, technological. Zucker (1986) posits that in the $19^{\text {th }}$ century institutional trust became the predominant basis for exchange because of the upheaval of immigration and technological change which increased the complexity of society. ${ }^{11}$ It is during this era that we see the growth of legislation and regulations and institutional intermediaries such as stock markets and banks.

Thus, in Zucker's (1986) perspective, the change in social and technological environment lead to 'demand' for trust. However, those researchers who stress the critical role of culture,

\footnotetext{
${ }^{11}$ Others will trace the importance of institutional trust further back. Fukuyama (2011) argues that it was already in medieval times when supply of trustworthy justice system was a single key factor making some of the kingdoms more successful than others. And off course the same argument would apply to antiquity, including the Roman Republic.
} 
will argue it another way around: it is the 'supply' of trust, and more generally a shift in cultural values that led to the modern wave of innovation and entrepreneurship (McCloskey, 2010; Mokyr, 2017).

Another perspective would be to argue, that both institutional trust and narrower groupbased trust may be the necessary conditions for entrepreneurship to thrive. Banfield (1958) documents a case of a local society, where a degree of protection is offered by state institutions, and that generates some institutional trust, yet at the same time the societal trust is missing; trust is only restricted to very narrow marriage-base, parents-children family structures ('amoral familism'). In such a world, there is some basic formal protection of contracts (typically, with high transaction costs). At the same time, within-group social and business cooperation is minimal, as the mutual social trust is missing. Entrepreneurship and innovation is lacking, and in the example explored by Banfield, this could not be explained by traditionalism either, as the church played little role as an institution, with limited social influence. Rather, the stagnant local economy was associated with the lack of narrower, local, societal trust that inhibited cooperation, innovation, and entrepreneurship (Banfield, 1958).

A story, which is parallel to this one, is that of the political and economic transition that followed the implosion of the Soviet system in Central and Eastern Europe. While state institutions were reformed to provide some security of contracts (to varying degree of success), the societal trust did not increase, at least not immediately, inhibiting entrepreneurship (Estrin and Mickiewicz, 2011). Strengthening formal institutions may also enhance the generalised trust, but the latter effect comes with delay. Trust takes time to become socially embedded and it is persistent over long periods of time (Guiso et al., 2010). Mickiewicz et al.(2017) discuss how the Soviet past continues to affect the attitudes both of business owners and entrepreneurs, and of government officials, resulting in low trust. 
More generally, the literature focused on extended trust (generalised trust and institutional trust) considers how differences in low and high trust environments impact on entrepreneurship (De Clercq et al., 2013; Fukuyama, 1995; Tilmar, 2006; Welter, 2012) and the strategies the entrepreneurs use to deal with low trust environments, such as relying on particular trust (Puffer et al. 2010). Aidis and Van Praag (2007) analyse the example of the informal entrepreneurship under Soviet regime, which again points to the substitution effects between the particular and the extended forms of trust. Interestingly, they also discuss how the informal entrepreneurship utilising particular trust structures was transformed into formal entrepreneurship, when the latter became legal.

For different reasons, the situation may be similar in other emerging market economies that undergo their own transition, with impact on entrepreneurship. Tillmar (2006: 102) observes that with respect to East Africa:

"Tanzania is a society in transition towards the post-traditional and modern or, expressed differently, towards a society where the aspect of Gesellschaft is becoming more salient relative to Gemeinschaft (Asplund 1991). Informal institutions have to a large extent been disrupted, but formal institutions have not become embedded and trusted by the citizens (Giddens 1990).”

Thus, again, here we have the case where formal institutions are reformed, yet societal trust is weak, albeit following a different scenario. Yet, there are also contrasting cases, where business cooperation and entrepreneurship are supported by societal forms of trust, despite dysfunctional state institutions and lack of independent, reliable judiciary. Such case is documented by Nee and Opper (2012), where Chinese new enterprises in coastal provinces, predominantly exporters, developed a system of informal norms and informal sanctions (especially: exclusion from further transactions) that support trust and cooperation. 
These business' structures of trust, substituting for institutional trust may be family-based. Trust between family members may compensate for weak formal institutions which could create trust between actors. Thus, we see a greater prevalence of family firms in less developed countries where formal institutions that can support entrepreneurship and business are weak or lacking, as families provide a level of trust and solidarity which is otherwise difficult to acquire (Soleimanof et al., 2018).

Thus, both societal and institutional trust matter, but while the former may sometimes substitute for the latter, it is actually more difficult to achieve it the other way round. It seems that the institutional trust enhances business cooperation, but the societal trust remains an important, separate prerequisite for entrepreneurship. It does not gets substituted away. ${ }^{12}$

Newton and Zmerli (2011) aim to shed some light on the interdependences between different forms of trust but the authors consider only democracies ${ }^{13}$. Their key result is this: particular trust conditions generalised (societal) trust; in turn the latter conditions political (institutional) trust. The reverse causation may exist, but it is weak at best. This implies that seeing particular and extended trust in opposition to each other may have no foundations in empirics. Yet, as already discussed, an approach based on Banfield (1958) would suggest even stronger separation between the types of trust: some elements of institutional trust may be there even if particular trust is missing.

\footnotetext{
${ }^{12}$ One may also observe that such asymmetric effects are very difficult to model using standard econometric techniques. This may call for different methodologies, especially when applied to country level studies, for example for the use of fuzzy set Comparative Qualitative Analysis that allows both for asymmetry and equifinality (Ragin, 2008; 2014; Schneider and Wagemann, 2012).

${ }^{13}$ For the reason: they argue that people answering political questions under autocracies are likely be dishonest, as being concerned with potential personal repercussions after giving answers that official agents of the authorities may not like; self-censorship is ubiquitous in such countries.
} 
The social group (and characteristics based) basis of trust also implies that trust may have its dark side. The other side of the strong shared trust within a particular social group may be both difficulty for the group members in establishing social and economic external contacts, and exclusion of outsiders in access to some critical resources and transactions. In this context, Fukuyama (2001) introduces the notion of the 'radius of distrust' that comes as a negative externality resulting from a narrow, strong radius of trust within a particular social group. This may be also exemplified by negative effects of trust structures concentrated on family in family businesses as discussed above (Arregle et al., 2007; Solimanof et al., 2018).

More generally, trustworthiness of individuals determines access to resources, yet it may be skewed across the society and it may differ both between social groups and according to the demographic characteristics like age and gender (Coleman, 1990). This may lead to relying on some specific forms of trust and narrower social circles of trust, so that the scope of transactions and mobility may be hampered (Morck and Yeung, 2004). Likewise, the groupbased structures of trust may be linked to social and business discrimination (Arneil, 2006).

However, Newton and Zmerli again challenge that theoretical consensus and observe the following (2011: 175): "Much of it assumes, at least implicitly, that in-group identity is necessarily associated with out-group hostility (cf. Brewer, 1999: 430), but recent work shows that in-group attachment is independent of attitudes towards out-groups. Distrust of out-groups depends partly on competition for resources, how much the in-group feels threatened, and on the trade-off between the benefits of closure of in-group boundaries versus the opportunities of opening up to outside groups (Brewer, 1979,1999, 2007; Yamagishi et al., 1998; Hewstone et al., 2002: 575-604; Voci, 2006)." This is in line with effects reported by Bertrand and Schoar (2006). While they found negative correlation between individuals' generalised trust and trust in family for some developing countries (e.g. Canada, US), for some developed countries there is positive correlation (e.g. Ghana, India). It could be 
therefore that the 'pecking order' of trust from particular to extended that Newton and Zmerli (2011) observed is characteristic for developing but not for developed countries, yet this would require further investigation.

Furthermore, Rothstein and Uslander (2005: 72, footnote 97) observe that diversity and exposure to outgroups leads to generalised trust. ${ }^{14}$ This in turn may enhance entrepreneurial opportunities. This theme is followed by Efendic et al. (2015) for entrepreneurs in Bosnia, and by Mickiewicz et al. (2019) for entrepreneurs in the UK. In both cases, pluralistic ethnic environments correlate with more entrepreneurship. The argument however is that this results not only (or even not predominantly) stem from access to diversified pools of resources but also (or mainly) from change in attitudes and values: exposure to those who are different makes us more tolerant and more trusting towards them; more tolerant towards new ways of doing things; and more willing to accept and engage in innovation. Therefore, also more entrepreneurship stems from that. Thus, diversity leads to a gradual shift in values and culture, more generalised trust, and more acceptance of innovation.

More generally, the circles of trust are likely to be related to cultural traits. And trust is just one cultural value that links with entrepreneurship. To have positive impact on entrepreneurship, it may need to be accompanied by other cultural values and related attitudes; trust will be more effective when those other cultural components, supporting entrepreneurial and business engagement are present as well (McCloskey, 2006). As already hinted, there may also be some tension between elements of culture: values, attitudes and beliefs supporting cooperation (including trust) may be difficult to align in full with those supporting innovation.

\footnotetext{
${ }^{14}$ For a more general discussion of factors of trust, see Newton and Zmerli (2011: 183).
} 


\section{Macro-micro and micro-macro linkages}

It follows from the distinction between the particular and the extended trust that studies of trust take place at different levels of analysis, even if in both cases trust always starts at the level of individual. Particular trust relates to individual's attitudes oriented towards other specific people, and next can be extended towards categories of people, or towards people seen as institutional agents (Newton and Zmerli, 2011; see above). There is also individual variation in extended trust, which may be missed with simple averaging. Nevertheless, trust may be seen as an attribute of specific groups of people, including regions and countries (Fukuyama, 1995). Thus, the literature on trust also analyses it at the meso and macro level as well as the micro level. As already mentioned, the social and spatial extent of trust may vary, it may also vary in degree to which it is anchored in space. Trust may be a feature of a local neighbourhood, of a region or a country, or it may be a feature shared within some social group that is scattered over space, or which spatial distribution is unknown or of secondary importance, as in internet-based social groupings. Thus, to fully understand the role of trust in the entrepreneurial process, we also need to have an understanding of the linkages between the macro and micro levels.

Above, we already discussed micro-macro processes of building trust, especially when there is social exposure to ethnic pluralism in a context of a democratic polity with low level of conflict. Similar to that, we mentioned Newton and Zmerli's (2011) results, which suggest that extended trust may be built on particular trust. However, macro-micro influences are also important. Rothstein and Uslander (2005) discuss macro-micro processes that may destroy trust. For them, 'social trust is of how people evaluate the moral fabric in their society' (Ibid.: 43). Restricting their story to its business- and entrepreneurship- related aspects, we may describe the following vicious circle. Dysfunctional government breeds mistrust and mistrust 
in business in particular, as wealth is seen as a result of privilege not a result of ability or effort. Next, low trust leads to aggressive, arbitrary redistributive policies that also hit entrepreneurship; these policies come instead of stable universal welfare systems based on widespread social solidarity. Such aggressive redistributive policies are not universal and have no systemic, rule-based design; instead, they are clientelistic that is they target specific political supporters: individuals or groups (Fukuyama, 2014). Rothstein and Uslander (2005) observe the following:

'Attributions of success in life matter for two reasons. First, the generalised trust depends heavily upon optimism and control - the beliefs that life is good and going to get better and that you can help make it better. When people fear for the future and see rising inequality, they are less likely to be optimistic. Believing that you need special luck to succeed means that you do not believe that you are the master of your own fate. This pessimism about personal control fate leads to lower levels of generalized trust in societies as diverse as the United States and Romania.' (Ibid., p. 69)

Parallel to this, they argue that there is little trust in hierarchical cultures (Ibid.: 47). Hierarchies break horizontal social connections resulting in less trust. People are only supposed to trust their superiors, but in practice they attempt to fall back on narrow circles of particular trust. There is no equality of opportunities, including access to entrepreneurial opportunities, as the rights to engage in any business and social activities are licenced by those with monopoly of violence. Estrin and Mickiewicz (2011) discuss such a societal culture of mistrust under the Soviet-type regimes, where the aim was to construct the society based only on hierarchical connections. In contrast, horizontal connections were broken, and so was trust, making social and business cooperation difficult. 
Hierarchical structures result in patron-client relationships that reward loyalty instead of independence, and breed corruption (Rothstein and Uslander (2005: 53). In turn, "corruption undermines the foundations of institutional trust that are needed for the development of trade and entrepreneurial and innovative activity" (Anokhin and Schulze, 2009).

It follows therefore, that there is a positive relationship between control of corruption, trust, and entrepreneurial and innovative activities across nations (Anokhin and Schulze, 2009). This is because entrepreneurs need to rely on others with whom they only have indirect contact. But also the decision to pursue entrepreneurial or innovative activity depends on the extent to which the entrepreneur is able to capture the value they have created. When corruption is present, it indicates the wider scale of opportunism. Entrepreneurs face a greatly increased risk that those involved in the value chain will be opportunistic and will appropriate profits to which the entrepreneur is entitled. In other words, generalised trust is low.

Furthermore, corruption makes enforcement of law less effective, it is risky therefore to rely on legal contracts. And other alternative foundations for trust such as affect, kinship (family) or ethnic identity limit the size of effective cooperation and expose entrepreneurs to greater risk of adverse selection. They may also lead to vicious circles when family network structures spill over into politics leading reinforcing corruption and ultimately leading to oligarchic structures that hamper new entry and entrepreneurship (Bertrand and Schoar, 2006), as already mentioned above.

However, Welter (2012: 201) observes that these processes do not need to be originating at macro level, say with government policies. Instead, for example, entrepreneurs' trusting behaviour may lead to change in the social norms and more trust at the general level. This recognition of such bottom-up influences of (social) entrepreneurship on societal norms, including those related to trust and social capital can also be found in Estrin et al.(2013). 
They argue that social entrepreneurship activity translates into stronger social norms of cooperation, in turn enhancing purely commercial forms of entrepreneurship as well.

How exactly these parallel macro and micro processes work? Kwon et al. (2013: 982) start with an observation that in communities with high level of trust, there are more selfemployed (see also: Bertrand and Schoar, 2006). Then they continue explaining the impact of social trust on entrepreneurship (Kwon et al., 2013: 982; 986-987):

'We suggest that the role social trust plays in self-employment and business formation is crucial at the community level of analysis for two reasons: (1) it encourages the free flow of information between social groups and (2) it helps small entrepreneurs overcome a lack of recognizability and well-defined reputation.' /.../ 'Our theory of community social capital suggests that social trust and connected voluntary associations are particularly beneficial to individuals whose services would otherwise have limited visibility or legitimacy. If so, these effects should be especially pronounced for community residents who are selfemployed but have not been able to initiate incorporated businesses.'

Thus, extended trust may be particularly important for socially vulnerable individuals and communities. Yet, this is not a full picture. Trust may be equally important for activities that heavily rely on intangible assets and rapid pace of innovation at the frontier. As Kwon et al. (2013: 983) observe: 'Silicon Valley had a communal spirit'. Furthermore, as already mentioned, entrepreneurial finance is trust-intensive (Arthurs and Busenitz, 2003). Ding et al. (2015) find that individuals are more likely to be angel investors in countries with higher levels of social trust.

Another detail related to the impact of societal trust on entrepreneurship is added by Pathak and Muralidharan (2016): the impact of societal trust has differential effect, conditional on type of entrepreneurship. They argue that while societal trust has positive impact on both 
social and commercial entrepreneurship, it is stronger on the former. This is because social entrepreneurship 'must rely more on community based resources' (Ibid.: 170).

Impact of societal trust may be moderated by individual characteristics. De Clercq et al. (2013) look at the interaction of institutions and personal resources (finance, human capital, social networks). They hypothesise that (generalised) trust moderates the relationship between personal resources and likelihood to start a business. They find the effect of resources being stronger in high trust countries, which makes entrepreneurs more confident and willing to use these resources in full. In addition, trust does positively moderate the effect of both human (weakly) and social capital (more strongly) but not of financial capital.

Last but not least, macro-micro influences also relate to the impact of theories that became translated into normative statements and influence business and entrepreneurship practice via education and public discussion. Ghoshal (2005) and Ghoshal and Moran (1996) argue that theories that stress opportunism (agency theory, transaction costs theory) acquire selffulfilling prophecies when translated into managerial practice. And stress on strong hierarchical mechanisms of governance and excessive monitoring and control change the dispositions of affected business partners (and employees). A mechanism of negative reciprocity emerges, where those who are subject to such practices may indeed start to behave opportunistically, due to their sense of unfairness.

The key issue here is the congruence of goals, and the cooperation being more common and relevant experience of entrepreneurs than the competition is, echoing the effectuation theory we discussed above (Sarasvathy, 2001). However, Arthurs and Busenitz (2003) argue that while theories that over-emphasise opportunism may be unrealistic when applied to entrepreneurship, so may stewardship theory have unrealistic assumptions. The latter assumes goal alignment between the cooperating parties; this may be the case. However, the theory 
may go too far when presuming the subordination of the goals of one party to another (stewards) in such a relationship. Arthurs and Busenitz (2003) discuss this in the context of entrepreneurial finance, focusing on relations between VCs and entrepreneurs.

To summarize, if Ghoshal's (2005) argument, calling for more balanced view of business and entrepreneurship not dominated by the narrow emphasis on opportunism and recognising the role of trust, becomes widely accepted, this may actually lead to more trust in real practice. 


\section{The role of new technology in enhancing (or replacing) trust}

Interestingly, today a new form of trust are being developed due to technological change being exploited by entrepreneurs. Botsman calls this distributed trust: "trust that flows laterally between individuals, enabled by networks, platforms and systems" (Botsman, 2017: 257). Entrepreneurs creating business platforms such as Airbnb and BlaBla Car are enabling us to connect to unknown individuals and rent an apartment or share a car ride in ways that we would not have done previously to the same degree, because many people would not trust to transact in this way with unknown strangers. Platforms not only connect people who have goods and services to offer but provide mechanisms to enable unknown individuals to trust each other, using mechanisms such as id verification, pre-payment, reviews. This reduces the information gap and uncertainty about the unknown and things going wrong, and builds trust, enabling transactions and what Botsman calls a "trust leap" - taking a risk on a new way of doing things. Sanctions and reputation mechanisms work to reduce the leap of trust needed, but uncertainty is still present and thus trust is still necessary for the transaction to occur. The wide scale these platforms and the trust they create enables more actors, and more small scale entrepreneurs in particular to enter the stage, such as suppliers on platforms like Etsy, eBay and Airbnb.

Theirer et al. (2016) contend that these kinds of platforms are market-based solutions to Akerlof's 'lemons problem' in which information asymmetries prevent mutually beneficial exchanges from occurring. Akerlof (1978) explained the lemons problems using the example of the used car market. Buyers are aware that poor quality used cars, 'lemons', exist but, they are unable to tell which of the used cars are lemons. This means there is an information asymmetry between the buyer and the seller as only the seller is aware of the quality of their car. As buyers do not know which sellers may be acting opportunistically (which offered cars are lemons), they are less willing to pay for a used car. This then discourages the sellers of higher quality cars to offer them for sale, which means both buyers and sellers lose out. Theirer 
et al. (2016) argue, however, that every information problem such as in the used car market provides an entrepreneurial opportunity as entrepreneurs can innovate to find solutions restoring a complete market. Nowadays, unlike the 1970s when Akerlof wrote about the 'lemons problem', the internet allows greater information to be shared among market participants. If we look at examples of the sharing economy such as Airbnb and BlaBla Car, they function through the provision of robust reputational feedback mechanisms such as reviews, ratings and referrals (ter Huurne et al., 2017).

Reputational mechanisms work in two ways (similar to bilateral mechanisms of processbased trust): first, providing information about a transaction partner, and second, offering a means of sanctioning a breach of trust. Thus, reputational mechanisms are based on similar logic that support more traditional forms of trust in business: they are based not on formal sanctions supported by coercion, but by reputational effects and by the key social sanction, which is the risk of being excluded from further transactions. Reputational feedback mechanisms are not new. Many different forms have been enabling trade throughout history such as seeking referrals, viewing credentials and seals of approval, trailing a product or service, getting guarantees or warrantees, and developing brand names and franchises (Theirer et al. 2016). These have also been the basis for entrepreneurial opportunities, for example in the $20^{\text {th }}$ century, third party organisations such as independent reviews, information bureaus, ratings agency and consumer advocacy group were established as organisations that collect and disseminate information about the quality of goods and services for interested potential buyers who pay for that information as it would be more costly or impossible for them to get the information themselves (ibid., 2016). However, the internet has lowered the transaction costs of acquiring relevant information and has led to an evolution in who is providing the feedback. In the past, the ratings and reviews were produced by professional experts, for example Which in the UK, or Consumer Reports in the USA; both organisations have their own testing labs to 
test an analyse products. Nowadays, the internet has enabled low-cost feedback mechanisms facilitating the reviews of the average consumer; for example Amazon uses 5 star ratings and reviews on the products sold; other businesses such as Yelp and Trip Advisor have been created on the basis of compiling reviews, the former on local businesses and the later on hotels, tourist sites and other travel related services (ibid., 2016). Now, there are many other platforms, such as AirBnB and BlaBla Car, that rely on peer reviews: both the seller and the buyer rate each other. Botsman (2017) gives the example how BlaBla Car enables trust to be built between buyers and sellers through reviews. Reviews help both drivers and riders, who are strangers to each other, to feel comfortable, stepping into a car with someone they do not know, mitigating the fear that people often have about hitch-hiking, the pre-sharing economy version of this service.

However, reputation mechanisms, whilst emphasised greatly in the literature, are not the only means by which trust is supported and online transactions are facilitated. Whilst in the academic literature reputation mechanisms are often seen as a key trust-generating mechanism, Ter Huurne et al. (2017), in their review on the antecedents of trust in the sharing economy and in $\mathrm{C} 2 \mathrm{C}$ e-commerce, find that other factors are at work too. Trust in the platform linking buyers and sellers is also an important determinant of trust in the sharing economy which can be enhanced by security measures and guarantees provided by the platform, the platform's website and service quality as well as its reputation (ter Huurne et al. 2017). As Charlie Aufmann (n.d.), design manager for Airbnb states, good platform design helps to minimise uncertainties and set expectations, which allows people to take the leap of trust to book to stay in a strangers home or to put their room up for rent. Control of what platform users can do on the platforms, and sanctions for not abiding by the rules set by that platform play a role in creating trust in platforms in a similar way as it occurs with institutions and institutional trust: this is achieved by providing formal mechanisms by which transactions are protected and regulated. Returning 
to the example of BlaBla Cars, prepayment can be seen as a form of control as riders are required to pay in advance and will not be reimbursed if fail to turn up for the ride. Prepayment plays an important part in enabling the market by discouraging people from booking rides and not turning up which then in turn encourages drivers to offer rides (Botsman, 2017). ${ }^{15}$

Botsman (2017) agrees that platforms play a crucial role in mitigating the risk that bad things will happen, and that trust in the sharing economy (as we can add $\mathrm{C} 2 \mathrm{C}$ e-commerce) has three layers: trust in the idea first, trust in platform provider second, and in other participants third. Whilst we might think that the idea of car-sharing is a good one, we have to also trust the company that provides the platform to ensure trustworthy people are on the platform, before we then place trust in the individual who is offering a ride on a platform (Botsman 2017). Trust in the platform must come first because it is the platform which creates the reputation mechanisms and other mechanisms which build the trust between the participants, and these are not so simple to build as one might first think. For example, Airbnb co-founder Joe Gebbia (2016) stresses the difficulties of creating a well-designed reputation system, as in the context of Airbnb it is hard for people to give bad reviews. Earlier work on trust makes a similar point. Kramer (1999: 576) highlights that third parties tend to only make partial disclosure about others which make the effect on trust of information received by others complex as not all information is to be or will necessarily be trusted. Airbnb made it easier to leave bad reviews by requiring both hosts and guests to complete reviews before revealing them to each other (Newman and Antin, 2016).

Furthermore, these reputation systems can be gamed with fake and manipulated reviews. $\mathrm{Hu}$ et al. (2012) estimated that around $10 \%$ of book reviews on Amazon.com were manipulated and recently the Competition and Markets Authority (2019) in the UK asked Ebay and

\footnotetext{
${ }^{15}$ All this is consistent with the transaction costs theory, where prepayment is seen as one key example of credible unilateral commitment (Williamson, 1985).
} 
Facebook to take action to stop the sale of fake reviews through their sites. Thus, users need to trust the platform is tackling these issues as it is difficult for them to verify themselves whether the reputation systems are working before completing a transaction. Consequently, the impact of a reputation on a decision whether to trust will vary according to the amount of trust accorded to the source of information of the reputation (Sztompka 1999: 74), in this case the amount of trust in the platform.

The importance of trust in the digital world can also be seen in the rise of social media influencers - individuals, who develop their own personal brands, obtain followers on the social media platforms and become "influencers" who can use their popularity to promote goods and services - either that they like or that they are paid to endorse. The trust here is another form of distributed trust as it is flowing laterally between the individuals - the influencer and their followers. The influencer has a reputation with their followers who then trust in the influencer's views and therefore are willing to trust products and services that they promote. This in turn can allow influencers to earn a living entirely from their social media postings. The fact that this form of endorsement is still effective in influencing buying decisions, shows that even with the amount of information that can be gathered on products and services through reviews, there is a social need for non-anonymous, personal, 'humanised', individual sources of opinion. 'Celebrity' endorsement is not a new strategy for promoting trust in a product, however, social media platforms, parallel to allowing for anonymous reputation mechanisms have also led to a new type of personal authorities that are established within horizontal communication, not by some narrower circle of gatekeepers, like leading fashion journals for example. It can also supplement the traditional celebrity endorsement process as exemplified by Kylie Jenner who has supplemented her fame gained from being on TV with a social media following, which she credits as the reason behind her successful cosmetic line (Kupelian and Kim, 2019). This 
business has made her the youngest "self-made" billionaire ever according to Forbes (Robehmed, 2019).

Another exemplification of distributed trust is algorithmic trust, based on blockchain technology (Hawlitschek et al. 2018), which some predict will upend the current organisation of our economies and create new opportunities for entrepreneurs (Tapscott and Tapscott, 2018; Chen, 2018). Tapscott and Tapscott (2018: 5) call blockchain 'the trust protocol', as it "enables mere mortals to manufacture trust through clever code". Nakamoto introduced the first blockchain technology Bitcoin, a peer-to-peer digital cryptocurrency, in 2009. Nakamoto described it as a "system based on cryptographic proof instead of trust, allowing any two willing parties to transact directly with each other without the need for a trusted third party." (Nakamoto, 2008: 1). That is, there is no need for banks, credit card companies or governments as institutional intermediaries in which transacting parties place their trust in this payment mechanism. Yet, Nakamoto seems to be going too far declaring that trust in the intermediating organisation is entirely replaced. Rather, it is trust in Bitcoin that replaces trust given to more traditional intermediaries.

Blockchain has far wider implications than bitcoin as it is a general purpose technology that can be used for far more than cryptocurrencies. It does this by creating a distributed ledger which permanently records all transactions over time in a chain of cryptographically secured blocks which cannot be changed without the consensus of all nodes in the network agreeing to what block of transactions gets added next. This provides a historical, immutable, consensually agreed and publicly verifiable record of past transactions which is governed by the system as a whole (Hawlitschek et al. 2018). Blockchain provides the ability to track the attributes of a transaction, settle trades and enforce contracts automatically across a wide range of digital assets. It reduces the transaction costs of trade as the attributes of the transaction or information of the agents and goods involved can be stored on the distributed ledger which can be cheaply 
and easily verified in real time by the market participants, without the need for an intermediary, thus reducing the verification costs involved in transactions such as ensuring that the buyer has money to pay for a good/service (Catalini and Gans, 2018).

Davidson et al. (2018) argue that blockchain does more than just reduce transaction costs; it is a technology that is a new type of economic institution allowing people to coordinate economic activity. It is an institution and not just an improvement in the way current institutions work (as suggested by Catlini and Gans 2018) “owing to the underlying technology possessing many of the underlying features of market capitalism itself: viz. property rights (ledger entry and private keys), exchange mechanisms (public keys and peer-to-peer networks), law (code) and finance (initial coin offerings)" (Davidson et al. 2018: 641). If so, the blockchain will fundamentally change the way trust is built and thus change the economy. Davidson et al. (2018) argue that cryptographically secured blockchains are "trustless" as they use a decentralised cryptographic protocol to produce consensus about what to add to the blockchain. This removes the need for trust as they remove the need for the need for third-party intermediaries such as governments, banks etc. which are trusted to keep and maintain centralised ledgers. However, whilst the protocol may remove the need to trust third party intermediaries and the risk that they will not act with integrity or benevolence, "trust in the intermediary is replaced by trust in the underlying code and consensus rules." (Catalini and Gans, 2018: 8) or "algorithmic trust" (Hawlitschek et al. 2018), as most users do not actually understand the processes underlying blockchain. Algorithmic trust is not enough in itself for blockchain-based systems to be adopted: research shows that users also develop trust in blockchain based technologies if the latter have legitimacy within their current institutional environment and are supported by third-party services (Ibid.).

Algorithmic trust in blockchain technology is seen by many to have far reaching implications for entrepreneurship (Chen, 2017; Tapscott and Tapscott, 2018). Not only is the technology a 
source of entrepreneurial opportunity with many new start-ups being created to exploit blockchain, but also blockchain technologies have the potential to restructure fundraising and investing as entrepreneurs may no longer need to rely on business angels and venture capitalists; instead new start-ups can raise money from initial coin offerings (ICOs) (Chen, 2017; Adhami et al. 2018). "Initial Coin Offerings (ICOs) can be defined as open calls for funding promoted by organizations, companies, and entrepreneurs to raise money through cryptocurrencies, in exchange for a "token" that can be sold on the internet or used in the future to obtain products or services and, at times, profit" (Adhami et al. 2018: 1). However, it is currently difficult to assess to what extent this will happen and to what extent this is part of the hype that often occurs around new technologies such as blockchain.

We are now in a position to summarize this discussion, utilising the terminology adopted in our review. As argued by Coleman (1990), building structures of trust may itself become a subject of entrepreneurial activity. When the new organisational solutions are found, trust is built, widening or building new markets, overcoming informational asymmetries between the buyers and the sellers of the type discussed by Akerlof (1978). This newly emerging trust has two key layers. First it takes a form of extended trust, or more exactly institutional trust; that is trust in the new platform/vehicle for transactions built by the entrepreneur(s). Second, the subject of the platform itself is to build particular trust between strangers engaging in transactions. The novelty here is that while this is particular, transaction-related, trust, it is narrowly process-based, that is based on the recorded reputation built on the market. These reputations mechanisms can reduce the role that individual characteristics play as a basis of this particular trust (Abrahao et al. 2017); in that sense platforms can reduce the space for prejudices, biases, and culturally-motivated exclusion. But this is not a given; it requires thoughtful engineering otherwise platforms can exacerbate pre-existing societal biases (Edelman et al. 2017). 
In our opinion, all this is trust. We side with the authors cited above who keep the terminology of trust, because the mechanism is socially based, and the key sanction is the social/business sanction of exclusion from further transactions, not a formal sanction supported by some government-sponsored coercion mechanism. At the same time, these new organisations, as any other markets, always operate in the shadow of the law, and borrow some legitimacy from the broader legal environment in which they operate: institutional trust that a participant places in the platform is always supported if not sustained by a more general institutional framework of a country of origin (or of institutional organisation, e.g. European Union). Furthermore, socially based reputation-building mechanisms are not the only one that generate markets on these platforms. They are supplemented by standard governance mechanism, such as prepayments, that has been long recognised as playing a key role enabling transactions (Williamson, 1985). Social logic of trust plays a key role here, but it is not the only logic. 


\section{Conclusions}

We may summarise our discussion using a simple framework, illustrated by Figure 1 below. The issue of trust first emerges between the founders of the new venture. Extensive literature on family firms discuss how trust is borrowed from outside the business, leading to (hopefully) more effective management and development of the new venture. We discussed both gains and potential drawbacks of such design. We did not pay much attention to founders-managers relations with their employees. It is an important topic, and the issue of trust is the key to it. However, the literature discusses it mostly in the context of SMEs ${ }^{16}$, not in the context of new firms, and it is the latter which is our primarily focus. Here, the focus of the literature should probably be expected, as at early stage of the venture, the roles within the entrepreneurial team are often blurred, and managers versus employees roles and relations gain more significance only later on.

Next, we have particular trust structures that are built by the new venture reaching out to its outside stakeholders. Here, we highlighted both effectuation and bricolage theories, concentrated on entrepreneurship as the process of new venture creation. We argued that both approaches may and should incorporate the perspective of trust to produce more complete insights. And again, we left the literature on the role of trust in SMEs aside, as not directly related to venture creation. ${ }^{17}$

Last but not least, all these relations of particular trust (within the new venture, and with external stakeholders and business partners) are embedded in the extended structures of generalised and institutional trust. These wider structures facilitate broader cooperation. Most

\footnotetext{
${ }^{16}$ For example: Schlosser (2015) discuss trust between owners-managers of SMEs and their key employees; Wee and Chua (2013) discuss trust between SMEs employees in the context of knowledge sharing.

${ }^{17}$ As an example: Fink and Kraus (2007) consider the role of trust in internalisation of SMEs.
} 
likely, the extended trust primarily effect is not to enhance entrepreneurship as such, but to enhance more productive, ambitious, growth-oriented forms of entrepreneurship. This is because the extended trust facilitates conditions for wider extent of cooperation. As argued above, it does not substitute for particular trust, rather it facilities and amplifies the effect of the latter.

$\{$ Figure 1\}

The entrepreneur starts with a situation of uncertainty. And building and utilising structures of trust we just described plays a critical role in absorbing this uncertainty. It is a critical part of a new venture formation process. The latter includes borrowing trust from family for the purpose of the new businesses, use of local social resources via bricolage, effectuation, securing finance, and finally relying and drawing upon the context of generalised trust and institutional trust to extent the scale and scope of business operations.

However, we would like to offer a note of caution. We need cooperation for the society to be viable and for businesses and entrepreneurs to realise their full potential, but sometimes more trust and cooperation is not desired, for example we want less trust and cooperation between criminals. So a priori, we cannot declare that greater trust and cooperation is always desirable. Also it is important to consider the counterfactual and the alternative. If the alternative of trust is distrust, the former seems superior. However, we may not want too much cooperation, as we want some competition because it fosters performance and innovation (Gambetta, 1988). Furthermore, excessive trust may run against developing capacities for critical thinking and for questioning the status quo, for quest for improvements. These themes emerges in the context of family firms and also in the relationship between investors and entrepreneurs, as we discussed above. 
What makes the field of research on entrepreneurship and trust fascinating is that as Botsman (2017) argues, we seem to be going through a fundamental shift of trust. Our trust has declined in institutions, yet we are showing more trust in individuals, strangers even, enabled by networks and platforms. Thus, it is not that we are entering the age of less trust in business and elsewhere, but we are seeing a shift of trust towards a wider distribution and a different pattern. We believe that understanding this process may be critical for entrepreneurship as a research field, and as business practice. But in which direction we should focus? What are the key directions for future research? What are the gaps and how to fill those?

We offer just three, subjectively chose suggestions. First, as we emphasised in the beginning, trust may be just one of many aspects of social and cultural reality that supports human cooperation and business cooperation in particular. There are others cultural and social characteristics that need to be explored in conjunction with trust, for example the role of solidarity and openness. Furthermore, we need to be aware that different types of entrepreneurship may be differentially effected by different elements. Innovative entrepreneurship in particular, may be enhanced by different social and cultural elements than other forms of entrepreneurship. Innovative entrepreneurship may benefit from diversity but if so, diversity itself may need to combined with some degree of social cohesion, to secure both cooperation and transmission of new knowledge and new ideas (and receptiveness to those).

Next, while the role of extended trust as ascendant of entrepreneurship is generally understood, what is not much researched upon is how entrepreneurial activity in a given space, if sustained over a longer period of time, can build trust, not only in business domain but also spilling over to other domains: those of social and political nature. 
Loops of both positive and negative feedback are possible. For example, Facebook is an interesting example as it aims to enable connectivity, yet over the last few years we have been seeing much negative fallout in relation to Facebook: fake news, algorithms that encourage socially isolated bubbles, and subsequently the effects that these have on democracies around the world, as well as the use of the platform to incite violence as with the Rohingya in Myanmar (Fink, 2008).

Whilst the example of Facebook shows the speed at which sometimes effects can manifest themselves, the impacts of entrepreneurial activities on trust are often long-term processes, and therefore they call for taking historical research in entrepreneurship more seriously. Long term perspective leads us naturally to the question of education, and also links to a wider issue in teaching entrepreneurship where we often fail to get our students to consider ethics, and more specifically the broader impact of any possible entrepreneurial venture on society. And finally, technological progress and internet-based forms of cooperation may call for radical rethinking of forms of trust and the linkages to new venture formation. We hinted at these issues in our summary at the end of the previous section. Some also argue that new forms of technology such as blockchain may also lead to radical reshaping of how new ventures are created and managed (Davis, 2016; Tapscott and Tapscott, 2017; 2018). We have seen that the ICT revolution has already reduced the need for vertical integration and enabled the rise of small businesses and new ventures (Audretsch and Thurik, 2001). The new platforms, which have been created by entrepreneurs to create multisided marketplaces, construct trust between their users, and between the platform and their users. The formation of this distributed trust has allowed many individuals to act as micro-entrepreneurs in the gig economy. It will be interesting to explore further how these changes impact on entrepreneurship more generally as the latest GEM study suggests that the gig economy may actually act as a stepping stone towards individuals starting their own businesses (Hart et al. 
2019). But also, more research needs to be done in terms of how platforms construct this distributed trust as well as how to enable trust to be built between strangers, which does not rely on characteristic-based trust, which often reinforces social biases such as racism. Crowdfunding platforms and the role of trust within them may be a particularly interesting areas for entrepreneurship researchers to focus on, as they provide finance to enable the creation and growth of new ventures.

At the same time, whilst digital platforms are changing our societies, space-based social structures remain important as the increasingly popular strand of research on entrepreneurial ecosystems indicates (e.g. Stam 2015; Spigel, 2017; Spigel and Harrison, 2018; Thompson et al. 2018). Spatially-based social structures come with more complete knowledge about business partners, more frequent contact, and high quality, face to face communication (Corradini et al. 2019). All this suggest that some forms of trust will also be anchored in space. Yet whilst the entrepreneurial ecosystems literature places much emphasis on the importance of interactions cooperation and local culture for enabling entrepreneurship, there is little discussion of the foundations for this cooperation. We believe more attention to trust could be helpful here. We do not understand in full how local (extended) trust affects not only entrepreneurship but also more specifically different types of entrepreneurship, including its most ambitious, growth and/or innovation-oriented forms. There is a need for more work on meso, regional level to capture these effects.

Overall, we think trust is central to entrepreneurship. 


\section{References}

Abrahao, B., Parigi, P., Gupta, A., \& Cook, K. S. (2017). Reputation offsets trust judgments based on social biases among Airbnb users. Proceedings of the National Academy of Sciences, 114(37), 9848-9853.

Adhami, S., Giudici, G., \& Martinazzi, S. (2018). Why do businesses go crypto? An empirical analysis of initial coin offerings. Journal of Economics and Business, (March), 0-1.

Aidis, R., \& Van Praag, M. (2007). Illegal entrepreneurship experience: Does it make a difference for business performance and motivation?. Journal of Business Venturing, 22(2), 283-310.

Akerlof, G. A. (1978). The market for "lemons": Quality uncertainty and the market mechanism. In P. Diamond \& M. Rothschild (eds.), Uncertainty in economics (pp. 235-251). San Diego: Academic Press.

Allen, M. R., George, B. A., \& Davis, J. H. (2018). A model for the role of trust in firm level performance: The case of family businesses. Journal of Business Research, 84, 34-45.

Anokhin, S., \& Schulze, W. S. (2009). Entrepreneurship, innovation, and corruption. Journal of Business Venturing, 24(5), 465-476.

Arneil, B. (2006). Diverse communities: The problem with social capital. Cambridge University Press, Cambridge.

Arregle, J. L., Hitt, M. A., Sirmon, D. G., \& Very, P. (2007). The development of organizational social capital: Attributes of family firms. Journal of Management Studies, 44(1), 73-95.

Arregle, J. L., Duran, P., Hitt, M. A., \& Van Essen, M. (2017). Why is family firms' internationalization unique? A meta-analysis. Entrepreneurship Theory and Practice, 41(5), 801-831.

Arrighetti, A., R. Bachmann and S. Deakin, 'Contract Law, Social Norms and Inter-Firm Cooperation', Cambridge Journal of Economics, 21, 1997, pp.171-95

Arthurs, J. D., \& Busenitz, L. W. (2003). The boundaries and limitations of agency theory and stewardship theory in the venture capitalist/entrepreneur relationship. Entrepreneurship Theory and Practice, 28(2), 145-162.

Audretsch, D. B., \& Thurik, A. R. (2001). What's new about the new economy? Sources of growth in the managed and entrepreneurial economies. Industrial and corporate change, 10(1), 267-315.

Aufmann (n.d.) Designing for Trust: Observations from my first year at Airbnb. Retrieved 17 July 2019 from https://airbnb.design/designing-for-trust/

Axelrod, R. 1984. The evolution of cooperation. Basic Books, New York.

Baker, T., \& Nelson, R. E. (2005). Creating something from nothing: Resource construction through entrepreneurial bricolage. Administrative Science Quarterly, 50(3), 329-366.

Bammens, Y., \& Collewaert, V. (2014). Trust between entrepreneurs and angel investors: Exploring positive and negative implications for venture performance assessments. Journal of Management, 40(7), 1980-2008. 
Banfield, E. C. (1958). The Moral Basis of a Backward Society. Chicago: Free Press.

Beck, S., \& Prügl, R. (2018). Family firm reputation and humanization: Consumers and the trust advantage of family firms under different conditions of brand familiarity. Family Business Review, 31(4), 460-482.

Bengtsson, O., \& Hsu, D. H. (2015). Ethnic matching in the US venture capital market. Journal of Business Venturing, 30(2), 338-354.

Bertrand, M., \& Schoar, A. (2006). The role of family in family firms. Journal of Economic Perspectives, 20(2), 73-96.

Botsman, R. (2017). Who can you trust?: how technology brought us together-and why it could drive us apart. Penguin UK.

Calabrò, A., Vecchiarini, M., Gast, J., Campopiano, G., De Massis, A., \& Kraus, S. (2018). Innovation in family firms: a systematic literature review and guidance for future research. International Journal of Management Reviews.

Caliendo, M., Fossen, F., \& Kritikos, A. (2012). Trust, positive reciprocity, and negative reciprocity: Do these traits impact entrepreneurial dynamics?. Journal of Economic Psychology, 33(2), 394-409.

Catalini, C., \& Gans, J. S. (2018). Some simple economics of the blockchain (No. w22952). National Bureau of Economic Research.

Chen, Y. (2018). Blockchain tokens and the potential democratization of entrepreneurship and innovation. Business Horizons, 61(4), 567-575.

Churchill, S. A. (2017). Fractionalization, entrepreneurship, and the institutional environment for entrepreneurship. Small Business Economics, 48(3), 577-597.

Coleman, J. S. (1990). Foundations of Social Theory. Harvard University Press, Cambridge, MA.

Competition and Markets Authority (2019) CMA expects Facebook and eBay to tackle sale of fake reviews. Retrieved from https://www.gov.uk/government/news/cma-expects-facebookand-ebay-to-tackle-sale-of-fake-reviews [17/07/2019].

Corbetta, G., \& Salvato, C. (2004). Self-serving or self-actualizing? Models of man and agency costs in different types of family firms: A commentary on "comparing the agency costs of family and non-family firms: Conceptual issues and exploratory evidence". Entrepreneurship Theory and Practice, 28(4), 355-362.

Corradini, C., Folmer, F., \& Rebmann, A. (2019) Listening to the buzz: exploring the link between firm creation and regional relational structures as reflected by social media.

Proceedings of the Seventy-ninth Annual Meeting of the Academy of Management. Online ISSN: 2151-6561

Dasgupta, P. (1988). Trust as a commodity. In D. Gambetta (ed.), Trust: Making and Breaking of Cooperative Relations, pp.49-71. Oxford University Press, Oxford.

Davidson, S., De Filippi, P., \& Potts, J. (2018). Blockchains and the economic institutions of capitalism. Journal of Institutional Economics, 1-20. 
Davis, G. F. (2016). Can an economy survive without corporations? Technology and robust organizational alternatives. Academy of Management Perspectives, 30(2), 129-140.

De Clercq, D., Lim, D. S., \& Oh, C. H. (2013). Individual-level resources and new business activity: The contingent role of institutional context. Entrepreneurship, Theory and Practice, 37(2), 303-330.

De Clercq, D., \& Sapienza, H. J. (2005). When do venture capital firms learn from their portfolio companies?. Entrepreneurship, Theory and Practice, 29(4), 517-535.

Delhey, J., Newton, K., \& Welzel, C. (2011). How general is trust in "most people"? Solving the radius of trust problem. American Sociological Review, 76(5), 786-807.

Ding, Z., Au, K., \& Chiang, F. (2015). Social trust and angel investors' decisions: A multilevel analysis across nations. Journal of Business Venturing, 30(2), 307-321.

Discua Cruz, A., Howorth, C., \& Hamilton, E. (2013). Intrafamily entrepreneurship: The formation and membership of family entrepreneurial teams. Entrepreneurship, Theory and Practice, 37(1), 17-46.

Dixit, A. (2004). Lawlessness and Economics: Alternative Institutions of Governance. Princeton: Princeton University Press.

Domurath, A., \& Patzelt, H. (2016). Entrepreneurs' assessments of early international entry: The role of foreign social ties, venture absorptive capacity, and generalized trust in others. Entrepreneurship, Theory and Practice, 40(5), 1149-1177.

Dyer, W. G. (2012). How to create trust in family firms and rebuild it when it's lost: implications for practice and research. In A. Carsrud \& M. Brännback (Eds.). Understanding Family Businesses (pp. 157-168). New York, NY: Springer.

Dworkin, R. (1977). Taking Rights Seriously. London: Duckworth.

Edelman, B., Luca, M., \& Svirsky, D. (2017). Racial discrimination in the sharing economy: Evidence from a field experiment. American Economic Journal: Applied Economics, 9(2), 122.

Eddleston, K. A., Chrisman, J. J., Steier, L. P., \& Chua, J. H. (2010). Governance and trust in family firms: An introduction. Entrepreneurship Theory and Practice, 34(6), 1043-1056.

Eddleston, K. A., \& Morgan, R. M. (2014). Trust, commitment and relationships in family business: Challenging conventional wisdom. Journal of Family Business Strategy, 5(3): 21316.

Efendic, A., Mickiewicz, T., \& Rebmann, A. (2015). Growth aspirations and social capital: Young firms in a post-conflict environment. International Small Business Journal, 33(5), 537561.

Estrin, S., \& Mickiewicz, T. (2011). Entrepreneurship in transition economies: The role of institutions and generational change. In: Minniti, M. (ed.) The dynamics of entrepreneurship: Evidence from the global entrepreneurship monitor data, Oxford: Oxford University Press, 181-208.

Fink, M., \& Kraus, S. (2007). Mutual trust as a key to internationalization of SMEs. Management Research News, 30(9), 674-688. 
Fink, C. (2018). Dangerous speech, anti-muslim violence, and facebook in myanmar. Journal of International Affairs, 71(1.5), 43-52.

Francis, D. H., \& Sandberg, W. R. (2000). Friendship within entrepreneurial teams and its association with team and venture performance. Entrepreneurship, Theory and Practice, 25(2), 5-26.

Fukuyama, F. (1995). Trust: The social virtues and the creation of prosperity. London: Penguin Books.

Fukuyama, F. (2001). Social capital, civil society and development. Third World Quarterly, 22(1): 7-20.

Fukuyama, F. (2011). The Origins of Political Order: From Prehuman Times to the French Revolution. London: Profile Books.

Fukuyama, F. (2014). Political order and political decay: From the industrial revolution to the globalization of democracy. London: Profile Books.

Gambetta, D. (1988). Can we trust trust? in D. Gambetta (ed.) Trust: Making and Breaking of Cooperative Relations, pp.49-71. Oxford University Press, Oxford.

Gebbia, J. (2016) How Airbnb designs for trust. Retrieved 17 July 2019 from https://www.ted.com/talks/joe gebbia how airbnb designs for trust?language=en

Gemmell, R. M., Boland, R. J., \& Kolb, D. A. (2012). The socio-cognitive dynamics of entrepreneurial ideation. Entrepreneurship, Theory and Practice, 36(5): 1053-1073.

Ghoshal, S. (2005). Bad management theories are destroying good management practices. Academy of Management learning \& education, 4(1), 75-91.

Ghoshal, S., \& Moran, P. (1996). Bad for practice: A critique of the transaction cost theory. Academy of management Review, 21(1), 13-47.

Goel, S., \& Karri, R. (2006). Entrepreneurs, effectual logic, and over-trust. Entrepreneurship, Theory and Practice, 30(4), 477-493.

Granovetter, M. (1973). The strength of weak ties. American Journal of Sociology, 5(1), 13601380.

Guiso, L., Sapienza, P., \& Zingales, L. (2010). Civic capital as the missing link. National Bureau of Economic Research Working Paper 15845.

Gulati, R. and Sytch, M. 2008. Does familiarity breed trust? Revisiting the antecedents of trust. Managerial and Decision Economics, 29(2-3):165-90.

Habbershon, T. G., \& Williams, M. L. (1999). A resource-based framework for assessing the strategic advantages of family firms. Family business review, 12(1), 1-25.

Harrison, R. T., Dibben, M. R., \& Mason, C. M. (1997). The role of trust in the informal investor's investment decision: An exploratory analysis. Entrepreneurship, Theory and Practice, 21(4), 63-81.

Hart, M., Bonner, K., Heery, L., Prashar, N., \& Levie, J. (2019) The Global Entrepreneurship Monitor: United Kingdom 2018 Monitoring Report. Retrieved 1 August 2019 from https://natwestbusinesshub.com/content/global-entrepreneurship-monitor-gig-economybusiness-leaders 
Hawlitschek, F., Notheisen, B., \& Teubner, T. (2018). The limits of trust-free systems: A literature review on blockchain technology and trust in the sharing economy. Electronic Commerce Research and Applications, 29, 50-63.

Hite, J. (2005) Evolutionary processes and paths of relationally embedded network ties in emerging entrepreneurial firms. Entrepreneurship, Theory and Practice, 29(1), 113-144.

Howorth, C., Rose, M., \& Hamilton, E. (2006). Definitions, diversity and development: Key debates in family business research. In M. Casson, B. Yeung, A. Cassu, \& N. Wadeson (Eds.), Oxford Handbook of Entrepreneurship (pp. 225-247). New York: Oxford University Press.

Hu, N., Bose, I., Koh, N. S., \& Liu, L. (2012). Manipulation of online reviews: An analysis of ratings, readability, and sentiments. Decision support systems, 52(3), 674-684.

Johnson, M. A., Stevenson, R. M., \& Letwin, C. R. (2018). A woman's place is in the... startup! Crowdfunder judgments, implicit bias, and the stereotype content model. Journal of Business Venturing, 33(6), 813-831.

Karri, R., \& Goel, S. (2008). Effectuation and over-trust: Response to Sarasvathy and Dew. Entrepreneurship, Theory and Practice, 32(4): 739-748.

Knight, F. H. (1921/2009). Risk, Uncertainty and Profit. Signalman Publishing, Orlando.

Kramer, R. M. 1999. Trust and distrust in organizations: Emerging perspectives, enduring questions. Annual Review of Psychology, 50: 569-98.

Kupelian, K. \& Kim, I. (2019, Jul 10). Kylie Jenner is the world's second highest-paid celebrity. Here's how she makes and spends her \$1 billion. Business Insider. Retrieved 31 July 2019 from https://www.businessinsider.com/kylie-jenner-kardashian-youngest-self-made-billionaireforbes-net-worth-fortune-2019-3? $\mathrm{r}=\mathrm{US} \& \mathrm{IR}=\mathrm{T}$

Kwon, S. W., Heflin, C., \& Ruef, M. (2013). Community social capital and entrepreneurship. American Sociological Review, 78(6), 980-1008.

Lane, C. 1998. Introduction: Theories and issues in the study of trust. In Lane, C. and Bachmann, R (eds.), Trust Within and Between Organizations, pp.1-30. Oxford University Press, Oxford.

Lewis, J. D., \& Weigert, A. (1985). Trust as a social reality. Social forces, 63(4), 967-985.

Matthews, C. H., Hechavarria, D., \& Schenkel, M. T. (2012). Family business: a global perspective from the panel study of entrepreneurial dynamics and the global entrepreneurship monitor. In Understanding family businesses (pp. 9-26). Springer, New York, NY.

Mayer, R. C., Davis, J. H., \& Schoorman, F. D. (1995). An integrative model of organizational trust. Academy of management review, 20(3), 709-734.

Maxwell, A. L., \& Lévesque, M. (2014). Trustworthiness: A critical ingredient for entrepreneurs seeking investors. Entrepreneurship Theory and Practice, 38(5), 1057-1080.

McAllister, D. J. (1995). Affect-and cognition-based trust as foundations for interpersonal cooperation in organizations. Academy of management journal, 38(1), 24-59.

McCloskey, D. N. (2006). Bourgeois Virtue. Chicago: University of Chicago Press.

McCloskey, D. N. (2010). Bourgeois Dignity: Why Economics Can't Explain the Modern World. Chicago: University of Chicago Press. 
McCloskey, D. N. (2016). Bourgeois equality: How ideas, not capital or institutions, enriched the world. Chicago: University of Chicago Press.

McPherson, M., Smith-Lovin, L., \& Cook, J. M. (2001). Birds of a feather: Homophily in social networks. Annual Review of Sociology, 27(1), 415-444.

Mickiewicz, T., Sauka, A., \& Stephan, U. (2016). On the compatibility of benevolence and self-interest: Philanthropy and entrepreneurial orientation. International Small Business Journal, 34(3), 303-328.

Mickiewicz, T., Rebmann, A., \& Sauka, A. (2017). To Pay or Not to Pay? Business Owners' Tax Morale: Testing a Neo-Institutional Framework in a Transition Environment. Journal of Business Ethics, 1-19.

Mickiewicz, T., Hart, M., Nyakudya, F., \& Theodorakopoulos, N. (2019). Ethnic pluralism, immigration and entrepreneurship. Regional Studies, 53(1), 80-94.

Mokyr, J. (2017). A Culture of Growth: the Origins of the Modern Economy. Princeton: Princeton University Press.

Morck, R., \& Yeung, B. (2004). Family Control and the Rent-Seeking Society. Entrepreneurship Theory and Practice, 28(4), 391-409.

Möllering, G. (2014). Trust, calculativeness, and relationships: A special issue 20 years after Williamson's warning. Journal of Trust Research, 4(1): 1-21.

Moro, A., Fink, M., Maresch, D., \& Fredriksson, A. (2018). Loan managers' decisions and trust in entrepreneurs in different institutional contexts. Entrepreneurship and Regional Development, 30(1-2), 146-172.

Nakamoto, S. (2008). Bitcoin: A peer-to-peer electronic cash system. https://bitcoin.org/bitcoin.pdf [last accessed 16/11/2018]

Nee, V., \& Opper, S. (2012). Capitalism from below: Markets and institutional change in China. Harvard University Press, Cambridge MA.

Newman, R. \& Antin, J. (2016) Building for Trust: Insights from our efforts to distill the fuel for the sharing economy. Medium. Retrieved 17 July 2019 from https://medium.com/airbnbengineering/building-for-trust-503e9872bbbb\#.trjndtmx3

Newton, K. and Zmerli, S. (2011). Three forms of trust and their association. European Political Science Review, 3(2):169-200.

Nooteboom, B. (1996). Trust, opportunism and governance: A process and control model. Organization studies, 17(6), 985-1010.

Nooteboom, B. (2002). Trust: Forms, foundations, functions, failures and figures. Edward Elgar, Cheltenham.

Parker, S. C. (2018). The Economics of Entrepreneurship. Cambridge: Cambridge University Press.

Pathak, S., \& Muralidharan, E. (2016). Informal institutions and their comparative influences on social and commercial entrepreneurship: The role of in-group collectivism and interpersonal trust. Journal of Small Business Management, 54(S1), 168-188. 
Peng, M. W., \& Jiang, Y. (2010). Institutions behind family ownership and control in large firms. Journal of management Studies, 47(2), 253-273.

Penrose, E. (2009 [1959]). The Theory of the Growth of the Firm. Oxford: Oxford University Press.

Pettersson, M. (1999). Förtroende i samverkan: en studie av småföretagare i ett regionalt utvecklingsprojekt (Linköping: Department of Management and Economics, Linköpings Universitet).

Popper, K. R. (1963). Conjectures and refutations, London: Routledge.

Puffer, S. M., McCarthy, D. J., \& Boisot, M. (2010). Entrepreneurship in Russia and China: The impact of formal Institutional voids. Entrepreneurship, Theory and Practice, 34(3): 441467.

Putnam, R. D. (2000). Bowling alone: America's declining social capital. In: L. Crothers \& C. Lockhart (Eds.). Culture and politics (pp. 223-234). Palgrave Macmillan, New York.

Ragin, C. C. (2009). Redesigning social inquiry: Fuzzy sets and beyond. University of Chicago Press, Chicago.

Ragin, C. C. (2014). The comparative method: Moving beyond qualitative and quantitative strategies. University of California Press, Oakland CA.

Raiser, M. (1999). Trust in transition. EBRD Working Paper No. 39.

Rebmann (2015). Trust in Hölscher, J., \& Tomann, H. (Eds.). (2015). Palgrave Dictionary of Emerging Markets and Transition Economics (pp. 522-544). Palgrave MacMillan, London.

Robehmed (2019, 5 March). At 21, Kylie Jenner Becomes The Youngest Self-Made Billionaire Ever, $\quad$ Forbes. $\quad$ Retrieved 31 July 2019 from https://www.forbes.com/sites/natalierobehmed/2019/03/05/at-21-kylie-jenner-becomes-theyoungest-self-made-billionaire-ever/.

Rothstein, B. (2004). Social trust and honesty in government: A causal mechanisms approach in Kornai, J., Rothstein, B. and Rose-Ackerman, S. (eds.) Creating trust in post-socialist transition, pp.13-30. Palgrave-MacMillan, Basingstoke.

Rothstein, B. and Stolle, D. (2012). The State and social capital: An institutional theory of generalized trust. Comparative Politics, 40(4):441-50.

Rothstein, B., \& Uslaner, E. M. (2005). All for all: Equality, corruption, and social trust. World Politics, 58(1), 41-72.

Saparito, P. A., Chen, C. C., \& Sapienza, H. J. (2004). The role of relational trust in banksmall firm relationships. Academy of Management Journal, 47(3), 400-410.

Sarasvathy, S. D. (2001). Causation and effectuation: Toward a theoretical shift from economic inevitability to entrepreneurial contingency. Academy of management Review, 26(2), 243-263.

Sarasvathy, S., \& Dew, N. (2008). Effectuation and over-trust: Debating Goel and Karri. Entrepreneurship, Theory and Practice, 32(4): 727-737.

Schlosser, F. (2015). Identifying and differentiating key employees from owners and other employees in SMEs. Journal of Small Business Management, 53(1), 37-53. 
Schneider, C. Q., \& Wagemann, C. (2012). Set-theoretic methods for the social sciences: A guide to qualitative comparative analysis. Cambridge: Cambridge University Press.

Schwartz, S. (2011). Values: Cultural and Individual. In: F. J. R. van de Vijver, A. Chasiotis, \& S. M. Breugelmans (Eds.), Fundamental questions in cross-cultural psychology. Cambridge: Cambridge University Press, 463-493.

Sen, A. K. (2009). The Idea of Justice. Harvard University Press, Cambridge MA.

Shi, H. X., Shepherd, D. M., \& Schmidts, T. (2015). Social capital in entrepreneurial family businesses: the role of trust. International Journal of Entrepreneurial Behavior \& Research, 21(6), 814-841.

Schulze, W. S., Lubatkin, M. H., Dino, R. N., \& Buchholtz, A. K. (2001). Agency relationships in family firms: Theory and evidence. Organization science, 12(2), 99-116.

Smith, D. a., \& Lohrke, F. T. (2008). Entrepreneurial network development: Trusting in the process. Journal of Business Research, 61(4): 315-322.

Soleimanof, S., Rutherford, M. W., \& Webb, J. W. (2018). The intersection of family firms and institutional contexts: A review and agenda for future research. Family Business Review, 31(1), 32-53.

Spigel, B. (2017). The Relational Organization of Entrepreneurial Ecosystems.

Entrepreneurship: Theory and Practice, 41(1), 49-72. Spigel, B., \& Harrison, R. (2018).

Toward a process theory of entrepreneurial ecosystems. Strategic Entrepreneurship Journal, 12(1), 151-168.

Stam, E. (2015). Entrepreneurial ecosystems and regional policy: a sympathetic critique. European Planning Studies, 23(9), 1759-1769.

Steier, L. (2001). Family firms, plural forms of governance, and the evolving role of trust. Family Business Review, 14(4), 353-367.

Stephan, U., Hart, M., Mickiewicz, T., \& Drews, (2015). Understanding Motivations for Entrepreneurship. BIS Research Paper No. 212. (Accessed at: https://assets.publishing.service.gov.uk/government/uploads/system/uploads/attachment_data /file/408432/bis-15-132-understanding-motivations-for-entrepreneurship.pdf).

Strauss, L. (1953). Natural Right and History. Chicago: University of Chicago Press.

Sztompka, P. 1999. Trust: A sociological theory. Cambridge University Press, Cambridge.

Tapscott, D., \& Tapscott, A. (2017). How blockchain will change organizations. MIT Sloan Management Review, 58(2), 10.

Tapscott, D., \& Tapscott, A. (2018). Blockchain revolution: how the technology behind bitcoin and other cryptocurrencies is changing the world. Penguin, London.

ter Huurne, M., Ronteltap, A., Corten, R., \& Buskens, V. (2017). Antecedents of trust in the sharing economy: A systematic review. Journal of Consumer Behaviour, 16(6), 485-498.

Theirer, A., Koopman, C., Hobson, A., \& Kuiper, C. (2015). How the internet, the sharing economy, and reputational feedback mechanisms solve the lemons problem. University of Miami Law Review, 70, 830. 
Thompson, T. A., Purdy, J. M., \& Ventresca, M. J. (2018). How entrepreneurial ecosystems take form: Evidence from social impact initiatives in Seattle. Strategic Entrepreneurship Journal, 12(1), 96-116. https://doi.org/10.1002/sej.1285

Tillmar, M. (2006). Swedish tribalism and Tanzanian entrepreneurship: Preconditions for trust formation. Entrepreneurship and Regional Development, 18(2), 91-107.

Tocqueville, A. de (1835/2003). Democracy in America. Penguin, London.

Uslaner, E. M. 2002. The moral foundations of trust. Cambridge University Press, Cambridge.

Weber, M. (2017[1924]). General economic history. Abingdon: Routledge.

Wee, J., \& Chua, A. (2013). The peculiarities of knowledge management processes in SMEs: the case of Singapore. Journal of Knowledge Management, 17(6), 958-972.

Welter, F. (2012). All you need is trust? A critical review of the trust and entrepreneurship literature. International Small Business Journal, 30(3), 193-212.

Williamson, O. E. (1985). The Economic Institutions of Capitalism: Firms, markets, relational Contracting. New York: Free Press.

Williamson, O. E. (1993). Opportunism and its critics. Managerial and Decision Economics. 14(2): 97-107.

Zahra, S. A., Hayton, J. C., \& Salvato, C. (2004). Entrepreneurship in Family vs. NonFamily Firms: A Resource-Based Analysis of the Effect of Organizational Culture. Entrepreneurship Theory and Practice, 28(4), 363-381.

Zucker, L. G. (1986). The production of trust: Institutional sources of economic structure, 1840-1920. Research in Organization Behavior, 8: 53-111. 
Figure 1. Entrepreneurship and trust framework

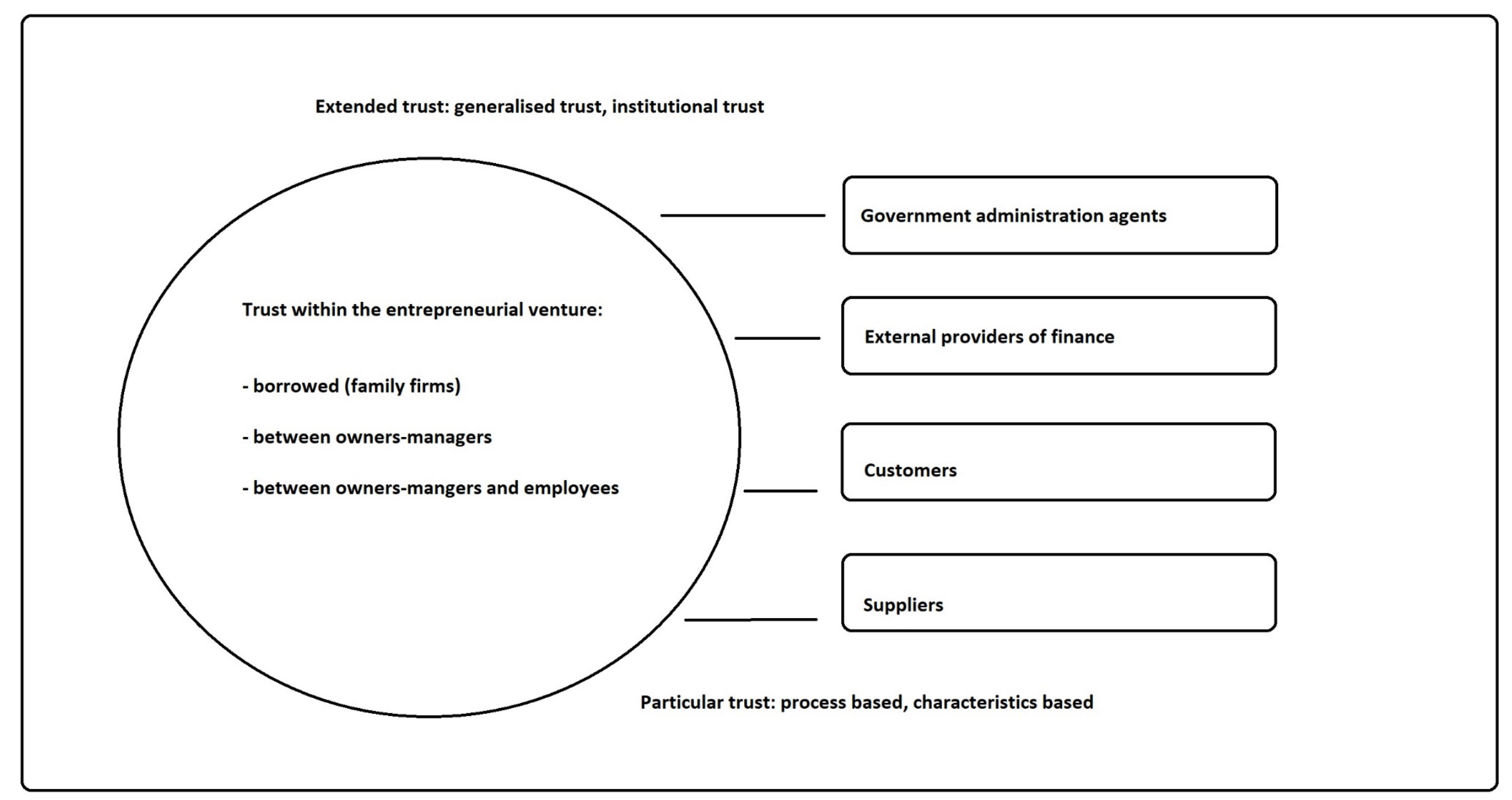

